\title{
PAPERS FROM ACTUARIAL JOURNALS WORLDWIDE
}

Single copies of all the papers listed here can be obtained, subject to charge and copyright regulations, from the actuarial profession's libraries. Issues may be borrowed by members. Tel: 01312401311 or 0207632 2114; libraries@actuaries.org.uk

\section{European Actuarial Journal}

$$
\text { 3(1), } 2013
$$

ALM, JONAS; LINDSKOG, FILIP. Foreign-currency interest-rate swaps in asset-liability management for insurers. 133-158. We consider an insurer with purely domestic business whose liabilities towards its policy holders have long durations. The relative shortage of domestic government bonds with long maturities makes the insurer's net asset value sensitive to fluctuations in the zero rates used for liability valuation. Therefore, in order to increase the duration of the insurer's assets, it is common practice for insurers to take a position as the fixed-rate receiver in an interest-rate swap. We assume that this is not possible in the domestic currency but in a foreign currency supporting a larger market of interest-rate swaps. Monthly data over 16 years are used as the basis for investigating the risks to the future net asset value of the insurer from using foreign-currency interest-rate swaps as a proxy for domestic ones in asset-liability management. We find that although a suitable position in swaps may reduce the standard deviation of the future net asset value it may significantly increase the exposure to tail risk that has a substantial effect on the estimation of the solvency capital requirements.

ASIMIT, ALEXANDRU V; BADESCU, ALEXANDRU M; TSANAKAS, ANDREAS. Optimal risk transfers in insurance groups. 159-190. Optimal risk transfers are derived within an insurance group consisting of two separate legal entities, operating under potentially different regulatory capital requirements and capital costs. Consistent with regulatory practice, capital requirements for each entity are computed by either a value-at-risk or an expected shortfall risk measure. The optimality criterion consists of minimising the risk-adjusted value of the total group liabilities, with valuation carried out using a cost-of-capital approach. The optimisation problems are analytically solved and it is seen that optimal risk transfers often involve the transfer of tail risk (unlimited reinsurance layers) to the more weakly regulated entity. We show that, in the absence of a capital requirement for the credit risk that specifically arises from the risk transfer, optimal risk transfers achieve capital efficiency at the cost of increasing policyholder deficit. However, when credit risk is properly reflected in the capital requirement, incentives for tail-risk transfers vanish and policyholder welfare is restored.

BANNOR, KARL F; SCHERER, MATTHIAS. Capturing parameter risk with convex risk measures. 97-132. Adequately specifying the parameters of a financial or actuarial model is challenging. In case of historical estimation, uncertainty arises through the estimator's volatility and possible bias. In case of market implied parameters, the solution of a calibration to market data might not be unique or the numerical routine returns a local instead of a global minimum. 
This paper provides a new method based on convex risk measures to quantify parameter risk and to translate it into prices, extending results in Cont (Math Finance 16(3):519-547, 2006) and Lindström (Adv Decision Sci, 2010). We introduce the notion of risk-capturing functionals and prices, provided a distribution on the parameter (or model) set is available, and present explicit examples where the Average-Value-at-Risk and the entropic risk measure are used. For some classes of risk-capturing functionals, the risk-captured price preserves weak convergence of the distributions. In particular, the risk-captured price generated by the distributions of a consistent sequence of estimators converges to the true price. For asymptotically normally distributed estimators we provide large sample approximations for risk-captured prices. Following BionNadal (J Math Econ 45(11):738-750, 2009); Carr et al. (J Financ Econ 62:131-167, 2001); Cherny and Madan (Int J Theor Appl Finance 13(8):1149-1177, 2010); Xu (Ann Finance 2:51-71, 2006), we interpret the risk-captured price as an ask price, reflecting aversion towards parameter risk. To acknowledge parameter risk in case of calibration to market prices, we create a parameter distribution from the pricing error function, allowing us to compare the intrinsic parameter risk of the stochastic volatility models of Heston and Barndorff-Nielsen and Shephard as well as the Variance Gamma option pricing model by pricing different exotics.

BAUERLE, NICOLE; PFEIFFER, ROBIN. A joint stock and bond market based on the hyperbolic Gaussian model. 229-248. In this paper, we introduce a joint bond and stock market model based on the state price density approach as a mean to discount future payments - whether these are stochastic dividend payments or secure repayments of government zerobonds. Based upon a recipe of Rogers [J Math Financ 7:157-176, 1997], we define a state price density model, the so-called Hyperbolic Gaussian model which allows for closed form zerobond prices and stock prices in an arbitrage-free way. It is particularly useful for insurance applications where large time horizons are considered. We estimate the joint factor model using the extended Kalman filter. The model we propose here is computationally much simpler than other models which have been considered in the literature.

DACOROGNA, MICHEL M; ALBRECHER, HANSJORG; MOLLER, MICHAEL; SAHITI, SUZANE. Equalization reserves for natural catastrophes and shareholder value: a simulation study. 1-21. This paper investigates the effects on the company value for shareholders of keeping equalization reserves for catastrophic risk in an insurance company. We perform an extensive simulation study to compare the performance of the company with and without equalization reserves for several standard profitability measures. Equalization reserves turn out to be beneficial for shareholders in terms of the resulting expected Sharpe ratio and also with respect to the value of the call option on assets at some reasonably large maturity time. Moreover, the expected total discounted tax payments are not smaller when using equalization reserves. The results are robust with respect to model parameters such as interest rate, time horizon, cost of raising capital and business cycle dynamics.

DEBON, A; MONTES, F; SALA, R. Pricing reverse mortgages in Spain. 23-43. In Spain, as in other European countries, the continuous ageing of the population creates a need for long-term care services and their financing. However, in Spain the development of this kind of services is still embryonic. The aim of this article is to obtain a calculation method for reverse mortgages in Spain based on the fit and projection of dynamic tables for Spanish mortality, using the Lee and Carter model. Mortality and life expectancy for the next 20 years are predicted using the fitted model, and confidence intervals are obtained from the prediction errors of parameters for the mortality index of the model. The last part of the article illustrates an application of the results to 
calculate the reverse mortgage model promoted by the Spanish Instituto de Crédito Oficial (Spanish State Financial Agency), for which the authors have developed a computer application.

DENUIT, MICHEL; HABERMAN, STEVEN; RENSHAW, ARTHUR E. Approximations for quantiles of life expectancy and annuity values using the parametric improvement rate approach to modelling and projecting mortality. 191-201. In this paper, we develop accurate approximations for medians of life expectancy and life annuity pure premiums viewed as functions of future mortality trends as predicted by parametric models of the improvement rates in mortality. Numerical illustrations show that the comonotonic approximations perform well in this case, which suggests that they can be used in practice to evaluate the consequences of the uncertainty in future death rates. Prediction intervals based on 5 and $95 \%$ quantiles are also considered but appear to be wider compared to simulated ones. This provides the practitioner with a conservative shortcut, thereby avoiding the problem of simulations within simulations in, for instance, Solvency 2 calculations.

DETERING, NILS; WEBER, ANDREAS; WYSTUP, UWE. Return distributions of equity-linked retirement plans under jump and interest rate risk. 203-228. We consider a savings plan, where the paid capital is guaranteed at time of retirement, in the German market available as Riester-Rente and supported by federal cash payments and tax benefits. We generalize several capital guarantee mechanisms to payment plans and compare their distribution: the return distribution of a classical insurance strategy with investments in the actuarial reserve fund, a CPPI strategy, and a Stop loss strategy, in optimistic, standard and pessimistic market scenarios. To model the distribution we use a jump diffusion process parameterized to resemble the MSCI World index for the stock investment and a Hull-White Extended Vasicek process, calibrated to the euro zero-bond curve, for the risk free investment. We also analyze how fee structures and gap risk affect the performance of these savings plans. Additionally, we present a very simple parameter estimation method for this kind of simulation studies.

LI, SHUANMING; SENDOVA, KRISTINA P. The finite-time ruin probability under the compound binomial risk model. 249-271. We study the compound binomial ruin model, which is considered to be the discrete analogue of the classical compound Poisson model. Our key result is a simple approach for inverting a generating function whose argument is the discount factor when we know the inverse of the same generating function, which this time has argument that is the solution to Lundberg's equation. The main idea comes from a result in Dickson and Willmot (ASTIN Bulletin 35:45-60, 2005) who discuss the classical model. We are then able to derive the probability distribution of the time to ruin and to go beyond the results in Dickson and Willmot (ASTIN Bulletin 35:45-60, 2005) by deducing the distribution of the first hitting time of a specific level and the duration of the time when the surplus is negative. The paper contains several illustrative examples where specific claim-amount distributions are considered.

NORBERG, RAGNAR. Quadratic hedging: an actuarial view extended to solvency control. 45-68. An investment strategy or portfolio is uniquely determined by an exposure process specifying the number of shares held in risky assets at any time and a cost process representing deposits into and withdrawals from the portfolio account. The strategy is a hedge of a contractual payment stream if the payments are currently deposited on/withdrawn from the portfolio account and the terminal value of the portfolio is 0 (ultimate settlement of the contractual liabilities). The purpose of the hedge is stated as an optimization criterion for the investment strategy. The purpose of the present paper is two-fold. Firstly, it reviews the core of quadratic hedging theory in a scenario 
where insurance risk can partly be offset by trading in available insurance-linked derivatives (e.g. catastrophe bonds or mortality bonds) and relates it to actuarial principles of premium rating and provision of reserves. Working under a martingale measure and some weak integrability conditions allows simple proofs based on orthogonal projections: quadratic hedging theory without agonizing pain. Secondly, it is pointed out that certain quadratic hedging principles lead to the same optimal exposure process but different optimal cost processes, special cases being mean-variance hedging and risk minimization. It is shown that these results are preserved if the value of the portfolio is required to coincide with a given adapted process, a case in point being the capital requirement introduced through regulatory regimes like the Basel accords and Solvency II.

ZAKS, YANIV. The optimal asset and liability portfolio for a financial institution with multiple lines of businesses. 69-95. In this paper we present an optimization framework to deal with the asset-liability portfolio selection problem. We consider a financial institution that has multiple lines of business. The capital allocation is obtained by minimizing the sum of the expected squared differences between the liability in each line of business and the value of the corresponding investment portfolio. We show that in certain circumstances the bottom-up approach is consistent with the top-down approach, where the optimal capital is determined for the whole portfolio rather than its individual components. Such a case happens for example if the same weight function is used for all lines of business in the two approaches. Finally, we obtain investment portfolios under some limitations on short sales.

\section{European Actuarial Journal}

$$
3(2), 2013
$$

BAUER, ACHIM; KRÜGER, RALF; OLBRICHT, WALTER. Tree-based methods: an application to disability probabilities. 491-513. Best estimate probabilities of the incidence of disability are a cornerstone of product development and the control cycle in contemporary life insurance practice. The identification of occupational classes with homogeneous risk profiles is of special interest and tends to be addressed by what are essentially heuristic approaches. This paper looks at the applicability of alternative statistics based methods and suggests the application of treebased methods to disability data. The interdependencies of influence variables and their impact as risk drivers for disability probabilities are studied. The paper assumes some familiarity with treebased methods, ideally knowledge of the companion article Olbricht (2012) [Olbricht, W. (2012), Tree-based methods: a useful tool for life insurance, European Actuarial Journal (2012) 2:129-147].

CHAI, CELESTE M H; SIU, TAK KUEN; ZHOU, XIAN. A double-exponential GARCH model for stochastic mortality. 385-406. In this paper, a generalized GARCH-based stochastic mortality model is developed, which incorporates conditional heteroskedasticity and conditional non-normality. First, a detailed empirical analysis of the UK mortality rates from 1922 to 2009 is provided, where it was found that both the conditional heteroskedasticity and conditional non-normality are important empirical long-term structures of mortality. To describe conditional non-normality, a double-exponential distribution that allows conditional skewness and the heavy-tailed features found in the datasets was selected. For the practical implementation of the proposed model, a two-stage scheme was introduced to estimate the unknown parameters. First, the Quasi-Maximum Likelihood Estimation (QMLE) method was employed to estimate the 
GARCH structure. Next, the MLE was adopted to estimate the unknown parameters of the double-exponential distribution using residuals as input data. The model was then back-tested against the previous 10 years of mortality data to assess its forecasting ability, before Monte Carlo simulation was carried out to simulate and produce a table of forecast mortality rates from the optimal distribution.

COSSETTE, HÉLÈNE; MAILHOT, MÉLINA; MARCEAU, ÉTIENNE; MESFIOUI, MHAMED. Bivariate lower and upper orthant value-at-risk. 321-357. Value-at-risk (VaR) is an important risk measure widely used in actuarial science and quantitative risk management. Embrechts and Puccetti (2006a) [Embrechts P., Puccetti G. (2006), Bounds for functions of multivariate risks, Journal of Multivariate Analysis 97(2):526-547] have introduced the multivariate lower and upper orthant VaR. The practical applications of these risk measures is very promising, especially in actuarial science and quantitative risk management. Our objective is to study in details the multivariate lower and upper orthant $\mathrm{VaR}$ in the bivariate setting, their properties and their applications. In particular, new characterizations of the bivariate lower and upper orthant VaR and desirable properties are given, such as translation invariance, positive homogeneity and comonotonic additivity. Lower and upper confidence regions for random vectors are developed and used to provide new results on the convexity conditions and to suggest capital allocation techniques. We provide bounds on functions of random pairs and derive interesting relations with existing results. We motivate the use of the bivariate lower and upper ortant VaR for risk allocation, to represent bivariate ruin probabilities and for risk comparison. Practical illustrations and examples of the results are presented throughout the article.

GIGANTE, PATRIZIA; PICECH, LIVIANA; SIGALOTTI, LUCIANO. Prediction error for credible claims reserves: an h-likelihood approach. 453-470. In this paper we consider a hierarchical overdispersed Poisson-gamma model for claims reserving as a hierarchical generalized linear model, in which the h-likelihood approach is applied to estimate the parameters. The model allows us to take account of external data, e.g. external estimates of ultimate claims. Predictions and prediction errors of the claims reserves are evaluated. For each origin year, the estimated reserve can be seen as a credible claims reserve: a mixture of a chain-ladder type and a Bornhuetter-Ferguson type claims reserve.

HONG, LIANG. Some remarks on capital allocation by percentile layer. 439-452. Capital allocation by percentile layer is a relatively new method. There is a claim that this method will generate different capital allocations than three other popular methods: CoVaR [Conditional Value-at-Risk], Alternative CoVaR and CoTVAR methods. It is also claimed that capital allocation by percentile allocates more capital to catastrophic perils that will cause more severe losses. We study these four methods formally. We show neither of the two claims holds in general. The results of this paper will provide actuaries and other financial risk analysts with valuable insights into capital allocation by percentile layer.

LÉVEILLÉ, GHISLAIN; HAMEL, EMMANUEL. A compound renewal model for medical malpractice insurance. 471-490. A renewal model for the aggregate discounted payments and expenses assumed by the insurer is proposed for the "medical malpractice" insurance, where real interest rates could be stochastic and the dependencies between the expenses, the payments and the delays of payment are examined through the theory of copulas. As a first approach to this problem, we present formulas for the first two raw moments and the first joint moment of this aggregate risk process. Examples are given for Erlang claims interoccurence times and delays of 
payment, Pareto payments and expenses, and the influence of the dependency is illustrated by the Joe copula. Finally the distribution, $\mathrm{VaR}$ and TVaR of our risk process are also considered through simulations.

PANTELOUS, ATHANASIOS A; PAPAGEORGIOU, ATHANASIOS. On the robust stability of pricing models for non-life insurance products. 535-550. One of the most significant and challenging problems in actuarial practice, especially for general insurance, is the modelling of the premium pricing process and furthermore its stability. The classical actuarial approach to calculating the premium simply covers the expected claims, with an increase for eventual expected surplus, chosen such that the portfolio can be considered stable. In this paper, we present an alternative model for the premium pricing process of a portfolio consisting of different non-life products. Moreover, a standard decision function for the determination of the premium is proposed based on the recent claim experience and a negative feedback mechanism of the known surplus value. The investigation of the robust stability of the system is performed via a Linear Matrix Inequality (LMI) criterion, permitting extensions of existing results. The novelty of the approach consists in the use of tools from the robust analysis of engineering systems in the insurance pricing process of non-life products into a discrete-time framework.

RAMSAY, COLIN M; SIMÕES, ONOFRE ALVES. Valuing the profit share in participating pure-endowment policies with return of premiums. 515-533. Solvency II together with changes in the accounting standards caused the valuation of future profit sharing in life insurance policies to become a problem with increasing significance and complexity. This happens because, apart from the structure of each contract itself and the associated profit sharing rules, the amount of profit to policy holders is a variable that depends on many other economic and financial factors. In this paper we value the profit share in with-profit and return of premiums pure-endowment policies, a particular case of practical interest not found in the literature. The need to follow Solvency II makes the valuation a difficult task and the major problem is to estimate all and each one of the cash flows generated by such contracts, till the maturity of the whole portfolio. A stochastic approach and a modified version of the Wilkie Model are the tools selected to perform the estimation.

RICHARDS, S J; KAUFHOLD, K; ROSENBUSCH, S. Creating portfolio-specific mortality tables: a case study. 295-319. Effective risk management of a portfolio demands accurate and succinct models which explain the main risk factors. Since portfolios have detailed individual records, an ideal approach is to use survival models. We look at a case study of how the administrator of a large multi-employer pension scheme created its own mortality tables. In addition to looking at statistical tests of fit, we consider a process for checking the suitability of a model for financial purposes. We also illustrate how a given scheme can test whether its experience is significantly different from other schemes, even after allowing for various known risk factors.

SCHLÖSSER, ANNA; ZAGST, RUDI. The Crash-NIG factor model: modeling dependence in credit portfolios through the crisis. 407-438. It is well known that the one-factor copula models are very useful for risk management and measurement applications involving the generation of scenarios for the complete universe of risk factors and the inclusion of CDO [collateralized debt obligation] structures in a portfolio context. For this objective, it is necessary to have a simple and fast model that is also consistent with the scenario simulation framework. In this paper we present three extensions of the NIG one-factor copula model which jointly have not been considered so far: (1) tranches with different maturities modeled in a consistent way, 
(2) a portfolio with different rating buckets, relaxing the assumption of a large homogeneous portfolio, and (3) different correlation regimes. The regime-switching component of the proposed Crash-NIG factor model is especially important in view of the current credit crisis. We also introduce liquidity premiums into the Crash-NIG factor model and show that the actual credit crisis is substantially driven by liquidity effects.

THONHAUSER, STEFAN. Optimal investment under transaction costs for an insurer. 359-383. We deal with the problem of minimizing the probability of ruin of an insurer by optimal investment of parts of the surplus in the financial market, modeled by geometric Brownian motion. In a diffusion framework the classical solution to this problem is to hold a constant amount of money in stocks, which in practice means continuous adaption of the investment position. In this paper, we introduce both proportional and fixed transaction costs, which leads to a more realistic scenario. In mathematical terms, the problem is now of impulse control type. Its solution is characterized and calculated by iteration of associated optimal stopping problems. Finally some numerical examples illustrate the resulting optimal investment policy and its deviation from the optimal investment behaviour without transaction costs.

Reproduced with the permission of Springer.

Subscription details available from: http://link.springer.com/contactus

http://link.springer.com/journal/13385

Geneva Papers on Risk and Insurance

38(3), 2013

BRAUN, ALEXANDER; MÜLLER, KATJA; SCHMEISER, HATO. What drives insurers' demand for cat bond investments?: evidence from a pan-European survey. 580-611. Although catastrophe bonds are continuing to gain importance in today's risk transfer and capital markets, little is known about the decision-making processes that drive the demand for this aspiring asset class. In the article at hand, we focus on one segment of the investor community. Our research goal is to identify major determinants of the cat bond investment decision of insurance and reinsurance companies. For this purpose, we have conducted a comprehensive survey among senior executives in the European insurance industry. Evaluating the resulting data set by means of exploratory factor analysis and logistic regression methodology, we are able to show that the expertise and experience with regard to cat bonds, the perceived fit of the instrument with the prevailing asset and liability management strategy, as well as the applicable regulatory regime are significant drivers of an insurer's propensity to invest. These statistical findings are supported by further qualitative survey results and additional information from structured interviews with the managers of four large dedicated cat bond funds.

CHANG, CHUN PING; BERDIEV, AZIZ N. Natural disasters, political risk and insurance market development. 406-448. We examine the relationship between natural disasters, political risk and insurance market development in a panel of 39 countries over the period 1984-2009 using a dynamic panel two-step system generalised method of moments model. We provide evidence that the incidences of natural disasters and deaths caused by natural disasters lead to greater total insurance, as well as life insurance and non-life insurance consumption. We also find that countries with lower levels of political risk experience higher insurance consumption. The incidences of natural disasters and deaths attributable to natural disasters contribute to insurance 
market development under the tenure of a government with lower levels of political risk. We therefore emphasise that natural disasters, political risk and their interaction effects are important determinants of insurance market development.

JAFFEE, DWIGHT; RUSSELL, THOMAS. The welfare economics of catastrophe losses and insurance. 469-494. This paper uses the tools of welfare economics to analyse the appropriate mix of private sector and government responses to catastrophic events. In particular, we examine the appropriate roles of post-disaster government aid, private insurance and mitigation activities. The analysis focuses on the distinction between the ex ante and ex post welfare criteria, as well as incentive issues such as may arise from the Samaritan's dilemma. A key factor is that individuals maintain differing subjective beliefs concerning the probability or magnitude of the catastrophic event. The analysis applies to insurance markets certain concepts that are now also being developed in the finance literature to examine the efficiency of naked credit default swaps and other instruments that are in essence side bets among agents with heterogeneous beliefs. We conclude that ex post welfare economics provides fundamental insights that have not been previously integrated into the discussions concerning the losses created by catastrophic events, including a potential role for mandatory insurance.

OU-YANG, CHIEH; KUNREUTHER, HOWARD; MICHEL-KERJAN, ERWANN. An economic analysis of climate adaptations to hurricane risk in St. Lucia. 521-546. We introduce a catastrophic risk model that captures the cumulative impact of climate change on future expected losses from hurricane risk. The annual growth rates of expected losses due to change in climate patterns (or "climate change factor") are estimated based upon historical storm activities in the Atlantic Basin and catastrophe modelling. The percentiles of the climate change factor are then used to measure expected hurricane losses in the Caribbean Island of St. Lucia. We also undertake benefit-cost analyses on four adaptation measures for homes in St. Lucia and determine when those are cost-effective for different time horizons and discount rates with and without climate change. Adaptation makes an enormous difference and can offset additional losses even with a high climate change factor by making houses much more resilient. Enforcing these protection measures will be critical.

REYNAUD, ARNAUD; AUBERT, CÉCILE; NGUYEN, MANH-HUNG. Living with floods: protective behaviours and risk perception of Vietnamese households. 547-579. We empirically investigate the determinants of household flood protective strategies and risk perception using data from a household-level survey conducted in spring 2012 in Vietnam. Our empirical analysis shows that some flood protective behaviours of Vietnamese households are driven by the perception of flood risks, a result consistent with the Protection Motivation Theory (PMT). Our results also suggest that both perceived probabilities and perceived consequences of floods are related to some cognitive processes included in the PMT. Lastly, we document the important role played by public flood management policies in shaping individual flood risk perception and protective behaviours.

TAKAO, ATSUSHI; YOSHIZAWA, TAKUYA; HSU, SHUOFEN; YAMASAKI, TAKASHI. The effect of the great east Japan earthquake on the stock prices of non-life insurance companies. 449-468. The Great East Japan Earthquake of 11 March 2011 incurred huge damages for Japan. This paper investigates how this earthquake influenced the value of Japanese insurance companies, especially non-life insurance companies. Our findings are as follows. (1) The stock prices of insurance companies decreased right after the earthquake. The spread of this decrease 
was less for the stock prices of non-life insurance companies than for those of life insurance companies. (2) The more capital buffer a non-life insurance company had, the higher the stock return. (3) The Earthquake Insurance System on Dwelling Risks in Japan not only indemnifies seismic losses but also functions as a Japanese stock market stabiliser.

TURVEY, CALUM G; GAO, XIN; NIE, RONG; WANG, LINPING; KONG, RONG. Subjective risks, objective risks and the crop insurance problem in rural China. 612-633. China's infant crop insurance industry faces two, not mutually exclusive, challenges. The first challenge is operational and arises from the lack of historical crop yield data at the farm household or village level. The second problem relates to a possible disconnect between objective measures of historical yields that is required for actuarial pricing in the supply of insurance and the subjective perceptions of future risk that is required to establish demand. This may require a substantial subsidy from the Chinese government in order to encourage participation. This paper examines both issues, including the form of subsidy, through use of the beta-PERT distribution. The PERT distribution has the advantage of defining proximal (second best) distributions based on farmers' recall of historical low, high and typical yields to cover objective risk measures, and subjective distributions through projections of low, high and most likely future yields. Direct elicitations of objective and subjective PERT parameters from 730 farmers in Shaanxi were collected in the fall of 2010. We find that 82.3 per cent of farm households have perceptions that their pro-forma corn yields in 2011 would be higher than their historical memory, while 71.63 per cent perceived the distribution of risks in 2011 to be lower than the historical average. In addition, we find that when we regress farmers' interest in crop insurance it is the skewness of subjective risk that matters, and perception of downside risk is largely dictated by perceived mean and standard deviation. As a result we argue that the need for subsidising crop insurance premiums is a consequence of the dissonance between subjective and historical risks.

XU, XIAN; MO, JIAWEI. The impact of disaster relief on economic growth: evidence from China. 495-520. In this paper we construct a simple two-period equilibrium model for analysing the impact of post-disaster transfer payments on economic growth. This model can be used to show that direct payment of disaster relief funds may aggravate rather than mitigate the negative impact of disasters on the economy. The substitution effect of direct transfer payment depresses post-disaster labour supply and hence economic growth. This conclusion from the theoretical model is tested using Chinese provincial panel data and applying generalised method of moments (GMM) system estimation. The empirical analysis largely confirms the theoretical predictions. In China, post-disaster transfer payments are indeed found to exacerbate the negative impact of disasters on economic growth. Therefore, we suggest that relief should be oriented to create work incentive in order to avoid its depressing effect on economic growth.

Geneva Papers on Risk and Insurance

38(4), 2013

BELLONI, MICHELE; MACCHERONI, FABIO. Actuarial fairness when longevity increases: an evaluation of the Italian pension system. 638-674. This study analyses the actuarial characteristics of the Italian pension system throughout its transition from defined benefit (DB) to notional defined contribution (NDC) rules, taking into account expected increasing longevity. Computations rely on ad hoc projected cohort mortality tables based on a limit survival scenario depicted by demographic experts. Most workers retiring in the coming years, whose pension is 
partly computed according to DB rules, will receive more-than-actuarially fair pensions. However, the generosity of the pension system has been significantly reduced for them by a recent reform that tightened early retirement eligibility requirements. Disability benefits remain (extremely) generous when claimed before age (57) 60. Steady-state NDC pensions, due to dynamic efficiency, are less than actuarially fair. They further deviate from actuarial fairness due to the specific rules, based on historical mortality, adopted by the Italian law for computing and updating benefits while facing increasing longevity. Cohort mortality projections should be used to handle longevity changes in NDC schemes.

CAPPELLETTI, GIUSEPPE; GUAZZAROTTI, GIOVANNI; TOMMASINO, PIETRO. What determines annuity demand at retirement? 777-802. We study the determinants of the demand for annuities using survey data from Italy. Eliciting potential demand with an ad hoc question, we are able, contrary to most previous studies, to disentangle demand from supply-side effects. Our results highlight the do importance of wealth, impatience, education and financial literacy in shaping annuity demand. In particular, not only do poor people annuitise less; they are also characterised by a higher elasticity of annuity demand to prices. This result suggests that prices higher than those actuarially fair should concern policymakers and regulators not only on efficiency, but also on fairness grounds.

ELING, MARTIN. Intergenerational transfers and the stability of the Swiss retirement system. 701-728. We analyse intended and unintended solidarity transfers between the young and the old in the Swiss retirement system. In addition to the intended solidarity transfers in the pay-as-yougo system, we identify a systematic unintended solidarity transfer from the active population to new retirees in the occupational pension system, which occurs due to the statutory conversion rates not being actuarially fair. After providing an overview of intergenerational transfers in Switzerland, we briefly review the Swiss retirement system. Then, we quantify the unintended transfer in the occupational pension system and finish by discussing several policy measures that could be implemented to avoid this intergenerational transfer. The unintended solidarity transfer casts some doubt on the financial stability and social acceptability of the Swiss retirement system, which is often considered one of the best in the world. As such, the problems of and recommendations for the Swiss system are of interest to other pension systems as well.

GOTO, SHINGO; NORIYOSHI, YANASE. Financial flexibility and tax incentives: evidence from defined benefit corporate pension plans in Japan. 753-776. Contrary to the objective of a major corporate pension reform in Japan to enhance retirement income security, and despite the increased relative tax benefits of externally-funded plans, the number of firms that do not sponsor externally-funded defined benefit plans or defined contribution plans has been increasing steadily. We study the common characteristics of firms sponsoring only traditional internally-funded lump sum plans that provide only weak protection of the employees' retirement benefits. We find that smaller firms with higher growth prospects (price-to-book ratios) and a younger workforce are less likely to adopt externally-funded plans and more likely to terminate them when they have one. Firms sponsoring only internally-funded plans tend to exhibit lower profitability than their peers with otherwise similar characteristics. These results suggest that smaller firms with higher growth prospects and a younger workforce tend to have stronger incentives to ensure financial flexibility by providing only weak protection of their employees' retirement benefits.

KANTARCI, TUNGA; SMEETS, INGRID A J; VAN SOEST, ARTHUR. Implications of full and partial retirement for replacement rates in a defined benefit system. 824-856. Flexible retirement 
arrangements in which workers can retire abruptly or gradually at the age of their choice with higher retirement income as a reward for working more or longer fit well with the changes in life course patterns in the past decades and may help to keep pension systems sustainable in times of population ageing. We analyse the flexibility of an existing pension arrangement in the Netherlands, characterised by a subsistence-level pay-as-you-go state pension combined with a supplementary occupational pension. We use the actual rules of a large occupational pension fund, the state pension and the tax system to calculate net replacement rates at ages 60 to 70 in full and partial retirement scenarios. We find that partial retirement results in a smoother income path and encourages employees to defer their pension claims beyond age 65. Moreover, while occupational pensions give close to actuarially fair rewards for continued full-time or part-time work, the state pension does not. This makes postponing retirement less attractive for low-income groups in particular.

OSTASZEWSKI, KRYSTZTOF. The effect of Pillar 1 on efficient investment portfolio choice in the case of the United States. 675-700. Pillar 1 of the U.S. retirement system is the Social Security system. It is both the largest social insurance system in the world and an important instrument of public policy. It provides universal retirement benefits based on wage history, and the number of years of service (up to 35 years). It is a core source of retirement income for American workers. In this paper, we consider this system as a part of capital markets, by asking how a person's optimal investment portfolio is affected by the existence of the Social Security System. We do this by calculating the optimal portfolio allocation at various levels of risk (i.e. the efficient frontier) for portfolios including a proxy for Social Security. This perspective is new in comparison to the existing literature on the subject. We show that the composition of the efficient frontier suggests arbitrage opportunities between Social Security and private capital markets, especially when portfolios optimal from the point of view of real returns are considered. We also note that exploitation of those opportunities may have important policy implications, as it may lead individual investors to treat Social Security as the "safe anchor" of their portfolio, and then taking more risk and assuming more leverage, in a potentially unsustainable fashion, in their remaining asset allocation.

OSTASZEWSKI, KRYSTZTOF; WEBB, ANTHONY. Guest Editorial: The Four Pillars: the next 25 years. 635-637. This special issue of The Geneva Papers on Risk and Insurance - Issues and Practice contains nine academic papers dealing with the challenge to retirement systems posed by ageing societies, slow economic growth, fiscal imbalances and the increasing cost of retirement. Although this issue has been overshadowed by the financial crisis, it is likely to become a major concern of political decision-makers and insurance industry leaders in the next quarter century. Almost exactly a quarter century ago, in 1987, The Geneva Association created a research programme devoted to global retirement challenges called the Four Pillars. The programme, now renamed Life and Pensions, noted that there are four main sources of income for retirees: State social security and social assistance systems (1st pillar); employment-based pensions (2nd pillar); private savings (3rd pillar) and continued employment (4th pillar). The Four Pillars programme celebrated its 25 th anniversary in 2012.

SUN, WEI; WEBB, ANTHONY. Should households base asset decumulation strategies on Required Minimum Distribution tables? 729-752. Retired households must trade off the risk of outliving their wealth against the cost of unnecessarily restricting their consumption. Using numerical optimisation techniques, we compare two innovative rules of thumb: (1) consuming the agerelated percentage of remaining wealth specified in the Internal Revenue Service (IRS) Required 
Minimum Distribution (RMD) tables, and (2) consuming the age-related percentage of remaining wealth specified in the IRS RMD tables PLUS interest and dividends, with alternative rules of thumb and with the theoretical optimal. We show that in models that incorporate uncertain investment returns, the second RMD strategy (spending age-related percentages of remaining wealth PLUS interest and dividends) performs better than plausible alternatives, such as spending the interest and dividends, consuming an inflation-indexed 4 per cent of initial wealth, or decumulating over the household's life expectancy. Importantly, except for more risk-averse single males, it also performs better than the purchase of a market-load inflation-indexed annuity, and approaches the theoretical optimum.

TIEN, JOSEPH J; MIAO, JERRY C Y. How households adjust their consumption and investment plans under longevity risk: an experimental approach-based study in Taiwan. 803-823. Longevity risk may be defined as the risk of outliving one's accumulated wealth. Although many theoretical studies have suggested that individuals will increase their precautionary saving in order to mitigate longevity risk, only a few of such studies have used empirical data to test people's decision-making behaviour in response to longevity risk. The main purpose of this paper is to investigate how households adjust their consumption and investment plans in response to longevity risk. We find that households reduce their consumption over their entire lifespan and increase the proportion of their risky assets before retirement when they face longevity risk. Furthermore, we also discover that households with females, more children, higher health expenditure and greater risk aversion change their risky assets to a lesser extent in their whole life period in the face of longevity risk, compared with other households.

ZHANG, YUE-HUA; LI, CHU-SHIU; PENG, SHENG-CHANG. The impact of health on work in China: a study using pilot survey data. 857-870. Using the China Health and Retirement Longitudinal Study pilot survey, this paper analyses the relationship between work and health in middle-aged and elderly people in China. Using an instrumental variable estimation and simultaneous equation model, this study confirms that health and pension system do matter to employment.

Reproduced with the permission of PalgraveMacMillan.

Subscription details available from: Palgrave Macmillan Subscription Department Tel: 144 (0)1256 357893, subscriptions@palgrave.com

http://www.palgrave-journals.com/pal/subscribe/index.html

Geneva Risk and Insurance Review

$38(1), 2013$

DOHERTY, NEIL. Risk and the endogenous economist: Some comparisons of the treatment of risk in physics and economics. 1-22. This is a talk, rather than a research or survey paper. Very little of what I say will be original, but I wish to stimulate discussion on a set of issues that arise from the nature of risk and that I consider problematic to our profession. The paper is not exhaustive of references and many of my arguments have been treated elsewhere. However, I suspect few will have approached the issues from the same starting point and assembled them in the same way.

LI, CHU-SHIU; LIU, CHWEN-CHI; PENG, SHENG-CHANG. Expiration dates in automobile insurance contracts: The curious case of last policy month claims in Taiwan. 23-47. This paper 
investigates a widespread trend in the Taiwanese automobile insurance market in which the loss claims of vehicle damage insurance contracts have a high propensity to occur just before the end of the policy year (as opposed to calendar year). We show that certain uncommon characteristics of claim data are consistently observed in the last policy month. We indirectly show that there is a severe time-varying excess claim problem in this market. The major sources of excess claims can be explained by the bonus-malus system problem and the auto-dealer incentive issue.

PICARD, PIERRE; PINQUET, JEAN. Optimal Risk Financing in Large Corporations through Insurance Captives. 48-86. A captive is an insurance or reinsurance company established by a parent group to finance its own risks. Captives mix internal risk pooling between the business units of the parent group and risk transfer towards the reinsurance market. We analyse captives from an optimal insurance contract perspective. The paper characterises the vertical contractual chain that links firstly business units to insurance captives or to "fronters" through insurance contracts, secondly fronters to reinsurance captives through the cession of risks and thirdly insurance or reinsurance captives to reinsurers through cessions or retrocessions. In particular, the risk cession by fronters to a reinsurance captive trades off the benefits derived from recouped premiums and from the risk-sharing advantage of an "umbrella reinsurance policy", against the risks that result from the captive liabilities.

RIAHI, DORRA; LEVY-GARBOUA, LOUIS; MONTMARQUETTE, CLAUDE. Competitive Insurance Markets and Adverse Selection in the Lab. 87-113. We provide an experimental analysis of competitive insurance markets with adverse selection. Our parameterised version of the lemons' model of Akerlof in the insurance context predicts total crowding-out of low risks when insurers offer a single full insurance contract. The therapy proposed by Rothschild and Stiglitz consists of adding a partial insurance contract so as to obtain self-selection of risks. We test the theoretical predictions of these two models in two experiments. A clean test is obtained by matching the parameters of these experiments and by controlling for the risk neutrality of insurers and the common risk aversion of their clients by means of the binary lottery procedure. The results reveal a partial crowding-out of low risks in the first experiment. Crowding-out is not eliminated in the second experiment and it is not even significantly reduced. Finally, instead of the predicted separating equilibrium, we find pooling equilibria. The latter can be sustained because insureds who objectively differ in their risk level do not perceive themselves as being so much different.

Reproduced with the permission of Palgrave MacMillan.

Subscription details available from: Palgrave Macmillan Subscription Department Tel: 144 (0)1256 357893, subscriptions@palgrave.com

http://www.palgrave-journals.com/pal/subscribe/index.html

Insurance: Mathematics \& Economics

$$
52(3), 2013
$$

ALAI, DANIEL H; LANDSMAN, ZINOVIY; SHERRIS, MICHAEL. Lifetime dependence modelling using a truncated multivariate gamma distribution. 542-549. Systematic improvements in mortality increases dependence in the survival distributions of insured lives, which is not accounted for in standard life tables and actuarial models used for annuity pricing and reserving. Systematic longevity risk also undermines the law of large numbers, a law that is relied on in the 
risk management of life insurance and annuity portfolios. This paper applies a multivariate gamma distribution to incorporate dependence. Lifetimes are modelled using a truncated multivariate gamma distribution that induces dependence through a shared gamma distributed component. Model parameter estimation is developed based on the method of moments and generalized to allow for truncated observations. The impact of dependence within a portfolio, or cohort, of lives with similar risk characteristics is demonstrated by applying the model to annuity valuation. Dependence is shown to have a significant impact on the risk of the annuity portfolio as compared with traditional actuarial methods that implicitly assume independent lifetimes.

CASCOS, IGNACIO; MOLCHANOV, ILYA. Choosing a random distribution with prescribed risks. 599-605. We describe several simulation algorithms that yield random probability distributions with given values of risk measures. In case of vanilla risk measures, the algorithms involve combining and transforming random cumulative distribution functions or random Lorenz curves obtained by simulating rather general random probability distributions on the unit interval. A new algorithm based on the simulation of a weighted barycentres array is suggested to generate random probability distributions with a given value of the spectral risk measure.

CHEN, MI; PENG, XIAOFAN; GUO, JUNYI. Optimal dividend problem with a nonlinear regularsingular stochastic control. 448-456. In this paper, a problem with a nonlinear regular-singular stochastic control is studied for a big insurance portfolio. We assume that the reinsurance premium is calculated according to the exponential premium principle which makes the stochastic control problem nonlinear. Both non-cheap and cheap reinsurance are investigated. The objective of the insurer is to determine the optimal reinsurance and dividend policy so as to maximize the expected discounted dividends until ruin. Bounded dividend rates and unbounded dividend rates are considered. In both cases, explicit expressions for the value function and the corresponding optimal strategies are obtained. Finally, a numerical example is presented, which shows the impacts of risk aversion of the reinsurance company on the optimal value function and the retention level for reinsurance.

CHUANG, O-CHIA; EECKHOUDT, LOUIS; HUANG, RACHEL J; TZENG, LARRY Y. Risky targets and effort. 465-468. When decision makers invest in effort to reach their targets, they face multiple sources of risk: first the risk of failure and second the noise that surrounds either the target or the initial situation. In this paper, we examine how effort is adjusted to account for changes in this risky environment.

COSSETTE, HELENE; COTE, MARIE-PIER; MARCEAU, ETIENNE; MOUTANABBIR, KHOUZEIMA. Multivariate distribution defined with Farlie-Gumbel-Morgenstern copula and mixed Erlang marginals: Aggregation and capital allocation. 560-572. In this paper, we investigate risk aggregation and capital allocation problems for a portfolio of possibly dependent risks whose multivariate distribution is defined with the Farlie-Gumbel-Morgenstern copula and mixed Erlang distribution marginals. In such a context, we first show that the aggregate claim amount has a mixed Erlang distribution. Based on a top-down approach, closed-form expressions for the contribution of each risk are derived using the TVaR and covariance rules. These findings are illustrated with numerical examples.

DEME, EL HADJI; GIRARD, STEPHANE; GUILLOU, ARMELLE. Reduced-bias estimator of the Proportional Hazard Premium for heavy-tailed distributions. 550-559. Many different premium principles have been proposed in the literature. In this paper, we focus on the Proportional 
Hazard Premium. Its asymptotic normality has been established in the literature under suitable conditions which are not fulfilled in the case of heavy-tailed distributions. We thus focus on this framework and propose a reduced-bias approach for the classical estimators. A small simulation study is proposed to illustrate the efficiency of our approach.

DHAENE, JAN; KUKUSH, ALEXANDER; LUCIANO, ELISA; SCHOUTENS, WIM; STASSEN, BEN. On the (in-)dependence between financial and actuarial risks. 522-531. Probability statements about future evolutions of financial and actuarial risks are expressed in terms of the 'real-world' probability measure P, whereas in an arbitrage-free environment, the prices of these traded risks can be expressed in terms of an equivalent martingale measure $\mathrm{Q}$. The assumption of independence between financial and actuarial risks in the real world may be quite reasonable in many situations. Making such an independence assumption in the pricing world however, may be convenient but hard to understand from an intuitive point of view. In this pedagogical paper, we investigate the conditions under which it is possible (or not) to transfer the independence assumption from $\mathrm{P}$ to $\mathrm{Q}$. In particular, we show that an independence relation that is observed in the P-world can often not be maintained in the Q-world.

DICKSON, DAVID C M; LI, SHUANMING. The distributions of the time to reach a given level and the duration of negative surplus in the Erlang(2) risk model. 490-497. We study the distributions of [1] the first time that the surplus reaches a given level and [2] the duration of negative surplus in a Sparre Andersen risk process with the inter-claim times being Erlang(2) distributed. These distributions can be obtained through the inversion of Laplace transforms using the inversion relationship for the Erlang(2) risk model given by Dickson and Li (2010). [D C M Dickson; S. Li, Finite time ruin problems for the $\operatorname{Erlang}(2)$ risk model, Insurance: Mathematics \& Economics (2010) 46: 12-18]

DIERS, DOROTHEA; LINDE, MARC. The multi-year non-life insurance risk in the additive loss reserving model. 590-598. The aim of this paper is to expand on recent contributions in the field of risk modelling for non-life insurance companies by modelling insurance risk in a multi-year context. Academic literature on non-life insurance risk to date has only considered an ultimo perspective (using traditional methods) and, more recently, a one-year perspective (for solvency purposes). However, strategic management in an insurance company requires a multi-year time horizon for economic decision making, providing the motivation for this paper. This is the first paper to derive analytically closed formulae for multi-year non-life insurance risk in the additive loss reserving model as defined by variation of multi-year claims development results. Embedding future accident years leads to an integrated approach to quantifying multi-year risk arising from the settlement of outstanding claims (reserve risk) and future claims yet to occur (premium risk). An application study will serve to illustrate the usefulness of the new multi-year horizon.

DINGEÇ, KEMAL DINÇER; HÖRMANN, WOLFGANG. Control variates and conditional Monte Carlo for basket and Asian options. 421-434. A new, very efficient and fairly simple simulation method for European basket and Asian options under the geometric Brownian motion assumption is presented. It is based on a new control variate method that uses the closed form of the expected payoff conditional on the assumption that the geometric average of all prices is larger than the strike price. The combination of that new control variate with conditional Monte Carlo and quadratic control variates leads to the newly proposed algorithm. Numerical experiments show that the new algorithm is more efficient than the classical control variate method using the geometric price. 
KALUSZKA, MAREK; KRZESZOWIEC, MICHAL. On iterative premium calculation principles under Cumulative Prospect Theory. 435-440. In the paper we analyze the iterativity condition for zero utility principle adjusted to Cumulative Prospect Theory. We prove, under mild conditions, that the premium principle is iterative if and only if the value function is linear or exponential and probability distortion functions are identities, i.e. the probabilities are not distorted.

LANDSMAN, ZINOVIY; PATA, NIKA; DHAENE, JAN. Tail Variance premiums for log-elliptical distributions. 441-447. In this paper we derive expressions for the Tail Variance and the Tail Variance Premium of risks in a multivariate log-elliptical setting. The theoretical results are illustrated by considering lognormal and log-Laplace distributions. We also derive approximate expressions for a Tail Variance-based allocation rule in a multivariate lognormal setting. A numerical example illustrates the accurateness of the proposed approximations.

PITSELIS, GEORGIOS. Quantile credibility models. 477-489. In this paper, we develop links between credibility theory and quantiles. More specifically, we show how quantiles can be embedded within the classical Bühlmann's (1967) [H. Bühlmann, Experience rating and credibility, ASTIN Bulletin, 4 (1967), pp. 199-207] credibility model and within Hachemeister's (1975) [C A Hachemeister, Credibility for regression models with application to trend, in Credibility, theory and applications, Proceedings Berkeley Actuarial Research Conference on Credibiilty, Academic Press, New-York, 1975] regression credibility model. The context of influence function is also incorporated into the above two models. For each model, credibility estimators are established and applications to real data are presented.

RAMSAY, COLIN M; OGULEDO, VICTOR I; PATHAK, PRIYA. Pricing high-risk and low-risk insurance contracts with incomplete information and production costs. 606-614. We consider the traditional model of an insurance market that consists of high-risk and low-risk individual customers who are identical except for their accident probabilities. Though insurers know the values of the high-risk and low-risk accident probabilities, each individual customer's accident probability is unknown to the insurer. It is well known that if individual customers have state-independent utility functions, and insurers incur neither production costs nor interest costs, then in competitive markets with imperfect information on accident probabilities, if an equilibrium exists it entails separate contracts with the high-risk individuals obtaining complete insurance and low-risk individuals obtaining partial insurance. While in monopolistic markets with imperfect information on accident probabilities, the following four properties hold: (i) highrisk and low-risk individuals never purchase the same insurance policy (i.e., pooling is never optimal); (ii) the optimal contract for the high-risk individual is complete insurance; (iii) if the low-risk individual buys insurance, his/her utility is essentially the same as it would have been had he/she not purchased any insurance; and (iv) there exists a critical (finite) ratio of high- to lowrisk individuals such that if the actual ratio exceeds the critical ratio, the low-risk individuals purchase no insurance. In this paper we will extend the traditional model by assuming that individual consumers have a common state-dependent utility function and assume insurers incur production costs that are proportional to the amount of insurance purchased and to the premium charged as well as interest costs. We derive results for both competitive markets and monopolistic markets with imperfect information on accident probabilities. We prove that even though pooling is never optimal in the traditional framework, it may be optimal in our model and high-risk individuals may optimally choose partial insurance. In addition, we develop extensions to the four properties listed above. 
TOMAS, JULIEN; PLANCHET, FRÉDÉRIC. Multidimensional smoothing by adaptive local kernel-weighted log-likelihood: Application to long-term care insurance. 573-589. We are interested in modeling the mortality of long-term care (LTC) claimants having the same level of severeness (heavy claimant). Practitioners often use empirical methods that rely heavily on expert opinions. We propose approaches not depending on an expert's advice. We analyze the mortality as a function of both the age of occurrence of the claim and the duration of the care. LTC claimants are marked by a relatively complex mortality pattern. Hence, rather than using parametric approaches or models with expert opinions, adaptive local likelihood methods allow us to extract the information from the data more pertinently. We characterize a locally adaptive smoothing pointwise method using the intersection of confidence intervals rule, as well as a global method using local bandwidth correction factors. The latter is an extension of the adaptive kernel method proposed by Gavin et al. (1995) to likelihood techniques. We vary the amount of smoothing in a location-dependent manner and allow adjustments based on the reliability of the data. Tests, and single indices summarizing the lifetime probability distribution are used to compare the graduated series obtained by adaptive local kernel-weighted log-likelihoods to p-spline and local likelihood models.

WANG, CHOU-WEN; HUANG, HONG-CHIH; HONG, DE-CHUAN. A feasible natural hedging strategy for insurance companies. 532-541. To offer a means for insurance companies to deal with longevity risk, this article investigates a natural hedging strategy and attempts to find an optimal allocation of insurance products. Unlike prior research, this proposed natural hedging model can account for both the variance and mispricing effects of longevity risk at the same time. In addition, this study employs experience mortality rates, obtained from life insurance companies, rather than population mortality data for life insurance and annuity products.

WENG, CHENGGUO. Constant proportion portfolio insurance under a regime switching exponential Levy process. 508-521. The constant proportion portfolio insurance is analyzed by assuming that the risky asset price follows a regime switching exponential Lévy process. Analytical forms of the shortfall probability, expected shortfall and expected gain are derived. The characteristic function of the gap risk is also obtained for further exploration on its distribution. The specific implementation is discussed under some popular Lévy models including the Merton's jump-diffusion, Kou's jump-diffusion, variance gamma and normal inverse Gaussian models. Finally, a numerical example is presented to demonstrate the implication of the established results.

YIN, CHUANCUN; WEN, YUZHEN. An extension of Paulsen-Gjessing's risk model with stochastic return on investments. 469-476. We consider in this paper a general two-sided jumpdiffusion risk model that allows for risky investments as well as for correlation between the two Brownian motions driving insurance risk and investment return. We first introduce the model and then find the integro-differential equations satisfied by the Gerber-Shiu functions as well as the expected discounted penalty functions at ruin caused by a claim or by oscillation. We also study the dividend problem for the threshold and barrier strategies, the moments and momentgenerating function of the total discounted dividends until ruin are discussed. Some examples are given for special cases.

ZENG, YAN; LI, ZHONGFEI; LAI, YONGZENG. Time-consistent investment and reinsurance strategies for mean-variance insurers with jumps. 498-507. This paper studies an optimal investment and reinsurance problem incorporating jumps for mean-variance insurers within a 
game theoretic framework and aims to seek the corresponding time-consistent strategies. Specially, the insurers are allowed to purchase proportional reinsurance, acquire new business and invest in a financial market, where the surplus of the insurers is assumed to follow a jump-diffusion model and the financial market consists of one risk-free asset and one risky asset whose price process is modeled by a geometric Lévy process. By solving an extended Hamilton-Jacobi-Bellman system, the closed-form expressions for the time-consistent investment and reinsurance strategies and the optimal value function are derived. Moreover, some special cases of our model and results are presented, and some numerical illustrations and sensitivity analysis for our results are provided.

ZHANG, LIANZENG; DUAN, BAIGE. Extensions of the notion of overall comonotonicity to partial comonotonicity. 457-464. The overall comonotonicity has become popular in actuarial science and finance over the last decade. As a further step, the notion of upper comonotonicity has recently been proposed. Using the technique of distributional representation we provide a unified method to extend the notion of comonotonicity further to lower comonotonicity, tail comonotonicity, and interval comonotonicity respectively. Numerical illustrations are provided to make a comparison among these different types of dependence structures. The numerical results can be explained to some extent by the sum of uniform $(0,1)(0,1)$ random variables, for which we obtain explicit formulae for the probability density functions of the sum of two random variables in partial comonotonicity cases. For higher dimension cases, it becomes complicated to find the corresponding explicit formulae.

Reproduced with the permission of Elsevier Science.

Subscription details available from: Elsevier Science, PO Box 311, 1000 AE Amsterdam, The Netherlands. E-mail: nlinfo-f@elsevier.nl

Journal of Risk and Insurance

80(2), 2013

BERRY-STÖLZLE, THOMAS R; HOYT, ROBERT E; WENDE, SABINE. Capital market development, competition, property rights, and the value of insurer product-line diversification: A cross-country analysis. 423-459. In this article, we show that the effect of product diversification on performance is not homogeneous across countries. Diversified insurance companies perform significantly worse than their focused competitors in countries with welldeveloped capital markets, high levels of property rights protection, and high levels of competition. In addition, we find that the diversification-performance relationship for insurance companies depends on company size. For large insurers operating in countries with less developed capital markets, diversification significantly increases performance. Our results suggest that the optimal organizational structure may be different for insurers operating in emerging economies than for insurers operating in developed countries.

BROEDERS, DIRK; CHEN, AN. Pension benefit security: A comparison of solvency requirements, a pension guarantee fund, and sponsor support. 239-272. Developed countries apply different security mechanisms in regulation to protect pension benefits: solvency requirements, a pension guarantee fund (PGF), and sponsor support. We compare these mechanisms for a generalized form of hybrid pension schemes. We calculate the expected log return for the beneficiaries, the shortfall probability, that is, the likelihood of the pension payment falling below the promised 
level and the expected loss given shortfall. Comparing solvency requirements to a pension guarantee system or sponsor support involves trading off risk and return. Additional spending on default insurance reduces the shortfall probability and the expected loss given shortfall but also lowers the probability of high positive returns as are feasible under solvency requirements.

\section{CARSON, JAMES M; MCCULLOUGH, KATHLEEN A; POOSER, DAVID M. Deciding whether} to invest in mitigation measures: evidence from Florida. 309-327. Prior research provides theoretical insight into factors likely to impact the decision to mitigate such as the degree of risk aversion, the cost of market insurance, and the cost of self-insurance. We provide empirical evidence related to several hypotheses from the self-insurance literature on the decision to mitigate.

FOCHT, UWE; RICHTER, ANDREAS; SCHILLER, JÖRG. Intermediation and (mis-)matching in insurance markets - who should pay the insurance broker? 329-350. This article addresses the role of independent insurance intermediaries in markets where matching is important. We compare fee-based and commission-based compensation systems and show that they are payoff equivalent if the intermediary is completely honest. Allowing for strategic behavior, we discuss the impact of remuneration on the quality of advice. The possibility of mismatching gives the intermediary substantial market power, which will not translate into mismatching if consumers are rational. Furthermore, we offer a rationale for the use of contingent commissions and address whether or not the ban of any commission payments is an appropriate market intervention.

GALEOTTI, MARCELLO; GÜRTLER, MARC; WINKELVOS, CHRISTINE. Accuracy of premium calculation models for cat bonds - an empirical analysis. 401-421. CAT bonds are of significant importance in the field of alternative risk transfer. Because the market of CAT bonds is not complete, the application of an appropriate pricing model is of high relevance. We apply different premium calculation models to compare them with regard to their predictive power. Without taking the financial crisis into account, a version of the Wang transformation model and the linear model are the most accurate ones. In contrast, under consideration of the financial crisis, all analyzed models are approximately equivalent. Furthermore, we find that CAT bond specific information does not improve out-of-sample results.

JONES, ROBERT A; PÉRIGNON, CHRISTOPHE. Derivatives clearing, default risk, and insurance. 373-700. Using daily data on margins and variation margins for all clearing members of the Chicago Mercantile Exchange, we analyze the clearing house exposure to the risk of default by clearing members. We find that the major source of default risk for a clearing member is proprietary trading rather than trading by customers. Additionally, we show that extreme losses suffered by important clearing firms tend to cluster, which raises systemic risk concerns. Finally, we discuss how private insurance could be used to cover the loss from defaults by clearing members.

OKHRIN, OSTAP; ODENING, MARTIN; XU, WEI. Systemic weather risk and crop insurance: the case of China. 351-372. This article explores the possibility of spatial diversification of weather risk for 17 agricultural production regions in China. We investigate the relation between the size of the buffer load and the size of the trading area of a hypothetical temperature-based insurance. The analysis adopts the hierarchical Archimedean copula approach that allows for flexible modeling of the dependence structure of insured losses. We find that the spatial diversification effect depends on the type of the weather index and the strike level of the insurance. Our findings are relevant for the current discussion on the viability of private crop insurance in China. 
SCHMEISER, HATO; WAGNER, JOËL. The impact of introducing insurance guaranty schemes on pricing and capital structure. 273-308. The introduction of an insurance guaranty scheme can have significant influence on the pricing and capital structures in a competitive market. The aim of this article is to study this effect on competitive equity-premium combinations while considering a framework with policyholders and equity holders where guaranty fund charges are volume-based, as levied in existing schemes. Several settings with regard to the origin of the fund contributions are assessed and the immediate effects on the incentives of the policyholders and equity holders are analyzed through a one-period contingent claim approach. One result is that introducing a guaranty scheme in a market with competitive conditions entails a shift of equity capital towards minimum solvency requirements. Hence, adverse incentives may arise with regard to the overall security level of the industry.

WISE, JACQUELINE VOLKMAN. Pension portfolio choice and peer envy. 461-489. I examine the effect of envy on the portfolio allocation of workers in a defined contribution (DC) pension plan. If a worker's DC plan performs better than his co-worker's, he may gloat; on the other hand, if his DC plan performs worse, he may feel envy. I model anticipated envy when workers make portfolio allocations, and find that in equilibrium, workers will mimic their co-worker's allocation to eliminate the disutility from envy. This portfolio allocation is riskier than that of a worker who does not exhibit envy.

Journal of Risk and Insurance

80(3), 2013

BIFFIS, ENRICO; BLAKE, DAVID. Informed intermediation of longevity exposures. 559-584. We examine pension buyout transactions and longevity risk securitization in a common framework, emphasizing the role played by asymmetries in capital requirements and mortality forecasting technology. The results are used to develop a coherent model of intermediation of longevity exposures, between defined benefit pension plans and capital market investors, through insurers operating in the pension buyout market. We derive several predictions consistent with the recent empirical evidence on pension buyouts and offer insights on the role of buyout firms and regulation in the emerging market for longevity-linked securities. A multiperiod version of the model is used to explore the effects of longevity risk securitization on the capacity of the pension buyout market.

BLAKE, DAVID; CAIRNS, ANDREW; COUGHLAN, GUY; DOWD, KEVIN; MACMINN, RICHARD. The new life market. 501-558. The huge economic significance of longevity risk for corporations, governments, and individuals has begun to be recognized and quantified. By virtue of its size and prevalence, longevity risk is the most significant life-related risk exposure in financial terms and poses a potential threat to the whole system of retirement income provision. This article reviews the birth and development of the Life Market, the new market related to the transfer of longevity and mortality risks. We note that the emergence of a traded market in longevity-linked capital market instruments could act as a catalyst to help facilitate the development of annuity markets both in the developed and the developing world and protect the long-term viability of retirement income provision globally.

BROCKETT, PATRICK L; CHUANG, SHUO-LI; DENG, YINGLU; MACMINN, RICHARD D. Incorporating longevity risk and medical information into life settlement pricing. 799-826. A life 
settlement is a financial transaction in which the owner of a life insurance policy sells his or her policy to a third party. We present an overview of the life settlement market, exhibit its susceptibility to longevity risk, and discuss it as part of a new asset class of longevity-related securities. We discuss pricing where the investor has updated information concerning the expected life expectancy of the insured as well as perhaps other medical information obtained from a medical underwriter. We show how to incorporate this information into the investor's valuation in a rigorous and statistically justified manner. To incorporate medical information, we apply statistical information theory to adjust an appropriate prespecified standard mortality table so as to obtain a new mortality table that exactly reflects the known medical information. We illustrate using several mortality tables including a new extension of the Lee-Carter model that allows for jumps in mortality and longevity over time. The information theoretically adjusted mortality table has a distribution consistent with the underwriter's projected life expectancy or other medical underwriter information and is as indistinguishable as possible from the prespecified mortality model. An analysis using several different potential standard tables and medical information sets illustrates the robustness and versatility of the method.

BROWN, JASON; WARSHAWSKY, MARK. The life care annuity: A new empirical examination of an insurance innovation that addresses problems in the markets for life annuities and long-term care insurance. 677-704. The life care annuity - the integration of the life annuity with long-term care insurance coverage - is intended to deal with major problems in the currently separate markets for life annuities and long-term care insurance. The integration would allow the inclusion of most of the population currently rejected by underwriting - those in poor health or lifestyles but who would not go immediately into long-term care claim - who also have lower life expectancies. We make use of the Health and Retirement Study, on individuals in retirement and their disability incidence, exploiting the panel nature of the survey to estimate transition probabilities in and out of disability states according to numerous demographic and health characteristics. This allows for analysis of disability and mortality risk across a number of dimensions. We find that different risk groups at age 65 have similar projected long-term care expenses, but that the level-periodic-premium structure of most long-term care insurance policies creates incentives for individuals to separate into different risk pools according to observable characteristics, justifying the underwriting observed on the market. Yet we also find that genderrated life care annuities could succeed in pooling risks currently segmented in the market for longterm care insurance, thus qualifying individuals at or near retirement for permanent long-term care insurance coverage who do not currently qualify, and allowing for life annuities to be purchased more cheaply than in the stand-alone annuity market now subject to adverse selection.

CAIRNS, ANDREW. Robust hedging of longevity risk. 621-648. We consider situations where a pension plan has opted to hedge its longevity risk using an index-based longevity hedging instrument such as a q-forward or deferred longevity swap. The use of index-based hedges gives rise to basis risk, but benefits, potentially, from lower costs to the hedger and greater liquidity. We focus on quantification of optimal hedge ratios and hedge effectiveness and investigate how robust these quantities are relative to inclusion of recalibration risk, parameter uncertainty, and Poisson risk. We find that strategies are robust relative to the inclusion of parameter uncertainty and Poisson risk. In contrast, single-instrument hedging strategies are found to lack robustness relative to the inclusion of recalibration risk at the future valuation date, although we also demonstrate that some hedging instruments are more robust than others. To address this problem, we develop multi-instrument hedging strategies that are robust relative to recalibration risk. 
CHEN, HUA; SHERRIS, MICHAEL; SUN, TAO; ZHU, WENGE. Living with ambiguity: Pricing mortality-linked securities with smooth ambiguity preferences. 705-732. Mortality is a stochastic process. We have imprecise knowledge about the probability distribution of mortality rates in the future. Mortality risk, therefore, can be defined in a broader term of ambiguity. In this article, we investigate the effects of ambiguity and ambiguity aversion on prices of mortality-linked securities. Ambiguity may arise from parameter uncertainty due to a finite sample of data and inaccurate old-age mortality rates. We compare the price of a mortality bond in three scenarios: (1) no parameter uncertainty, (2) parameter uncertainty with Bayesian updates, and (3) parameter uncertainty with the smooth ambiguity preference. We use the indifference pricing approach to derive the minimum ask price and the maximum bid price, and adopt the economic pricing method to compute the equilibrium price that clears the market. We reveal the connection between the indifference pricing approach and the economic pricing approach and find that ambiguity aversion has a much smaller effect on prices of mortality-linked securities than risk aversion in our example.

COX, SAMUEL H; LIN, YIJIA; TIAN, RUILIN; YU, JIFENG. Managing capital market and longevity risks in a defined benefit pension plan. 585-620. This article proposes a model for a defined benefit pension plan to minimize total funding variation while controlling expected total pension cost and funding downside risk throughout the life of a pension cohort. With this setup, we first investigate the plan's optimal contribution and asset allocation strategies, given the projection of stochastic asset returns and random mortality evolutions. To manage longevity risk, the plan can use either the ground-up hedging strategy or the excess-risk hedging strategy. Our numerical examples demonstrate that the plan transfers more unexpected longevity risk with the excess-risk strategy due to its lower total hedge cost and more attractive structure.

MAURER, RAIMOND; MITCHELL, OLIVIA S; ROGALLA, RALPH; KARTASHOV, VASILY. Lifecycle portfolio choice with systematic longevity risk and variable investment-linked deferred annuities. 649-676. This article assesses the impact of variable investment-linked deferred annuities (VILDAs) on lifecycle consumption and portfolio allocation, allowing for systematic longevity risk. Under a self-insurance strategy, insurers set premiums to reduce the chance that benefits paid exceed provider reserves. Under a participating approach, the provider avoids taking systematic longevity risk by adjusting benefits in response to unanticipated mortality shocks. Young households with participating annuities average one-third higher excess consumption, while 80-year-olds increase consumption about 75 percent. Many households would prefer to participate in systematic longevity risk unless insurers can hedge it at a very low price.

WANG, CHOU-WEN; HUANG, HONG-CHIH; LIU, I-CHIEN. Mortality modeling with non-Gaussian innovations and applications to the valuation of longevity swaps. 775-798. This article provides an iterative fitting algorithm to generate maximum likelihood estimates under the Cox regression model and employs non-Gaussian distributions - the jump diffusion (JD), variance gamma (VG), and normal inverse Gaussian (NIG) distributions - to model the error terms of the Renshaw and Haberman () (RH) model. In terms of mean absolute percentage error, the RH model with non-Gaussian innovations provides better mortality projections, using 1900-2009 mortality data from England and Wales, France, and Italy. Finally, the lower hedge costs of longevity swaps according to the RH model with non-Gaussian innovations are not only based on the lower swap curves implied by the best prediction model, but also in terms of the fatter tails of the unexpected losses it generates. 
ZHOU, RUI; LI, JOHNNY SIU-HANG; TAN, KEN SENG. Pricing standardized mortality securitizations: A two-population model with transitory jump effects. 733-774. Mortality dynamics are subject to jumps that are due to events such as wars and pandemics. Such jumps can have a significant impact on prices of securities that are designed for hedging catastrophic mortality risk, and therefore should be taken into account in modeling. Although several singlepopulation mortality models with jump effects have been developed, they are not adequate for modeling trades in which the hedger's population is different from the population associated with the security being traded. In this article, we first develop a two-population mortality model with transitory jump effects, and then we use the proposed model and an economic-pricing framework to examine how mortality jumps may affect the supply and demand of mortalitylinked securities.

ZHU, NAN; BAUER, DANIEL. Coherent pricing of life settlements under asymmetric information. 827-851. Although life settlements are advertised to deliver a profitable investment opportunity with a low correlation to market systematic risk, recent investigations reveal a discrepancy of expected and realized returns. While thus far this discrepancy has been attributed to the (allegedly) poor quality of the underlying life expectancy estimates, we present a different explanation of the seemingly high reported expected returns based on adverse selection. In particular, we provide a coherent pricing mechanism and pricing formulas in the presence of asymmetric information with respect to the underlying life expectancies. Therefore, our study sheds light on the nature of the "unique risks" within life settlements as recently discussed in the financial press.

Reproduced with the permission of the American Risk and Insurance Association.

Subscription details available from: the American Institute for CPCU, 720 Providence Road, Malvern, PA 19355, USA. E-mail: aria@cpcuiia.org

\section{North American Actuarial Journal}

$$
17(1), 2013
$$

BOOTH, PHILIP. State pension reform in a public choice framework. 82-97. Social security systems for old age have been explicitly studied in a public choice framework for more than 30 years. They illustrate extremely well the problems of allocating economic resources through a system of voting. Despite actuarial interest in state pension systems and despite the actuarial calculations that are needed to understand long-term public choice trends, there is almost no reference to public choice economics in the actuarial pensions literature. It can be argued that pension systems currently provide some of the most significant threats to the long-term budget positions of developed countries, a point that was made in the Nobel Laureate lecture of Professor James Buchanan over 24 years ago. In this article, we look at the costs and benefits that will be faced by different groups of voters as a result of state pension reform in the United Kingdom. The results of this analysis suggest that a majority of the electorate will have a strong financial interest in opposing state pension reform except where reform involves raising retirement ages. These results are in accordance not just with theoretical work but with other empirical work and practical observations.

GENEST, CHRISTIAN; CARABARÍN-AGUIRRE, ALBERTO. A digital picture of the actuarial research community. 3-12. The evolution of publication patterns in actuarial research is 
described through a survey of the contents of four peer-reviewed journals identified in several studies as the most influential in the field, including the North American Actuarial Journal. The research output of countries and institutions is compared over the 30-year period 1982-2011 on the basis of the number of articles and pages published, adjusted for journal page size. While simple counts such as these are only a cursory measure of productivity, and certainly not a measure of quality, they lead to rankings that broadly reflect the level of activity in actuarial research worldwide. Countries and institutions that are most active in the field are easily identified from these rankings. Such information is valuable to governmental funding agencies and administrators in academia or industry responsible for the quantitative assessment of research performance. Young researchers and prospective graduate students may also find it useful to acquaint themselves with the breadth of the actuarial research community.

NG, ANDREW CHEUK-YIN; LI, JOHNNY SIU-HANG. Pricing and hedging variable annuity guarantees with multiasset stochastic investment models. 41-62. Variable annuities are often sold with guarantees to protect investors from downside investment risk. The majority of variable annuity guarantees are written on more than one asset, but in practice, single-asset (univariate) stochastic investment models are mostly used for pricing and hedging these guarantees. This practical shortcut may lead to problems such as basis risk. In this article, we contribute a multivariate framework for pricing and hedging variable annuity guarantees. We explain how to transform multivariate stochastic investment models into their risk-neutral counterparts, which can then be used for pricing purposes. We also demonstrate how dynamic hedging can be implemented in a multivariate framework and how the potential hedging error can be quantified by stochastic simulations.

PANNING, WILLIAM H. Managing the invisible: identifying value-maximizing combinations of risk and capital. 13-28. This article demonstrates the linkage - often asserted but seldom described - between Enterprise Risk Management (ERM) and maximizing a firm's value. I show that knowing a firm's aggregate risk exposure (via ERM), when combined with a valuation model like the one presented here, can enable the firm's managers to identify and choose valuemaximizing combinations of risk and capital. Using value maximization as the criterion for choosing a firm's capital structure is quite distinct from rules of thumb that CFOs often use for such decisions. The valuation model shows that increasing an insurer's surplus from an initially low level typically increases the present value of future cash flows that take into account the probability of impairment from extreme losses. In contrast to traditional literature on the risk of ruin, impairment here is taken to mean a loss of creditworthiness such that the firm's business model is no longer sustainable, whether or not the firm is solvent. However, beyond a certain optimal level relative to a firm's risk, further increases in surplus actually reduce a firm's value added measured in this fashion. Sensitivity analyses presented here show how these conclusions are affected by changes in the values of crucial variables. In particular, the article shows how managers can use this model to identify specific actions that their firm can take to increase its value added, and it emphasizes the practical importance of making a firm's value both visible and manageable.

RAMSAY, COLIN M; ARCILA, LUIS DAVID. Pricing funeral (burial) insurance in a microinsurance world with emphasis on Africa. 63-81. Funeral (burial) insurance is one of the most common microinsurance policies sold in Africa. Funeral insurance is important because it pays for the cost of funeral arrangements, thus forming an important part of protection for lowincome workers. We develop a model of a microinsurance market in an African context where 
funeral insurance policies are sold to low-income households through a burial society, which contracts with a risk-neutral profit-maximizing monopolistic insurer to supply funeral insurance policies. We assume the burial society is sufficiently large that it has bargaining power and can negotiate on behalf of its members. The burial society requires that the insurer offer separate policies that are affordable to both low-risk and high-risk individuals and waiting periods cannot exceed $\mathrm{m}$ months. Applicants for insurance are identical except for their mortality, which is known to the insurer except for a single parameter called the frailty parameter. As death benefits and premiums are low, the insurer cannot afford to use a costly but effective underwriting technology to provide accurate information on each applicant's future mortality. To mitigate the effect of adverse selection, the insurer uses a simple low-cost practical underwriting strategy that requires all applicants to complete a questionnaire on their personal/family medical history, certify their "good health," and confirm that they are gainfully employed. The insurer also includes a waiting period before policyholders are eligible for death benefits. As there is no established actuarial theory that suggests how the optimum waiting period should be determined, the objective of this article is to establish a sound basis for determining both the premium and the waiting period for these policies. To this end we develop a discounted expected utility model of consumption by members of a burial society and use this model to determine the optimal premiums and waiting periods subject to solvency, lapse, and participation constraints.

YANG, CHARLES C. The impact of the interest rate on insurancelfinancials industries: the analysis of the stock market's reactions to Federal funds rate changes. 29-40. Taking an event-study approach, this article examines the impact of the interest rate on the insurance industry and its subindustries in contrast with other financials industries through the analysis of the stock market's reactions to federal funds rate changes. In addition to calculating the stock market's reaction on event days, this article analyzes market over- or underreaction by examining the stock market's responses on the following days. Furthermore, the stock market's reaction on days preceding event days is explored to test pre-announcement effects. This article also investigates asymmetries in responses of insurance and financials stock markets to certain characteristics of federal rate changes. This research provides important insights to investors, regulators and policymakers, and the management of insurance and financials companies in understanding the link between monetary policy and asset prices and the policy transmission mechanism particularly related to insurance and financials industries.

North American Actuarial Journal

$17(2), 2013$

BAYRAKTAR, ERHAN; YOUNG, VIRGINIA R. Life insurance purchasing to maximize utility of household consumption. 114-135. We determine the optimal amount of life insurance for a household of two wage earners. We consider the simple case of exponential utility, thereby removing wealth as a factor in buying life insurance, while retaining the relationship among life insurance, income, and the probability of dying and thus losing that income. For insurance purchased via a single premium or premium payable continuously, we explicitly determine the optimal death benefit. We show that if the premium is determined to target a specific probability of loss per policy, then the rates of consumption are identical under single premium or continuously payable premium. Thus, not only is equivalence of consumption achieved for the households under the two premium schemes, it is also obtained for the insurance company in the sense of equivalence of loss probabilities. 
FIER, STEPHEN G; LIEBENBERG, ANDRE P. Life insurance lapse behaviour. 153-167. Life insurance policy lapses are detrimental to issuing insurers when lapses substantially deviate from insurer expectations. The extant literature has proposed and tested, using macroeconomic data, several hypotheses regarding lapse determinants. While macroeconomic data are useful in providing a general test of lapse determinants, the use of aggregate data precludes an analysis of microeconomic factors that may drive the lapse decision. We develop and test a microeconomic model of voluntary life insurance lapse behavior and provide some of the first evidence regarding household factors related to life insurance lapses. Our findings support and extend the prior evidence regarding lapse determinants. Consistent with the emergency fund hypothesis we find that voluntary lapses are related to large income shocks, and consistent with the policy replacement hypothesis we find that the decision to lapse a life insurance policy is directly related to the purchase of a different life insurance policy. We also find that age is an important moderating factor in the lapse decision. Changes in income appear to more directly affect the decision to lapse for younger households, while they are generally unrelated to the lapse decision for older households.

LIU, XIAOMING. Annuity uncertainty with stochastic mortality and interest rates. 136-152. Risk analysis in actuarial science has shifted its focus from diversifiable risk to systematic risk in the last 20 years or so. This article contributes further in this direction by proposing the concept of annuity rate to take account of systematic risk inherent in annuity products. The annuity rate is the conditional expectation of the annuity's future payments, given the future paths of mortality and interest rates. We provide an empirical study to investigate the impact of the two systematic risk factors on the distribution of the annuity rate. In particular, we adopt the Lee-Carter and the Cairns-Blake-Dowd models for mortality risk, and the one-factor and two-factor CIR models for interest risk. Monte Carlo simulation is used to provide numerical illustrations of sensitivity analysis of the annuity rate and of risk assessment of a guaranteed annuity option.

MARTINEZ MIRANDA, MARIA DOLORES; NEILSEN, JENS PERCH; VERRALL, RICHARD. Double Chain Ladder and Bornhuetter-Ferguson. 101-113. In this article we propose a method close to Double Chain Ladder (DCL) introduced by Martínez-Miranda, Nielsen, and Verrall (2012a). The proposed method is motivated by the potential lack of stability of the DCL method (and of the classical Chain ladder method [CLM] itself). We consider the implicit estimation of the underwriting year inflation in the CLM method and the explicit estimation of it in DCL. This may represent a weak point for DCL and CLM because the underwriting year inflation might be estimated with significant uncertainty. A key feature of the new method is that the underwriting year inflation can be estimated from the less volatile incurred data and then transferred into the DCL model. We include an empirical illustration that illustrates the differences between the estimates of the IBNR and RBNS cash flows from DCL and the new method. We also apply bootstrap estimation to approximate the predictive distributions.

TANG, YUNFUN. Polynomial approximation to option prices under regime switching. 168-179. In this article we obtain the option pricing results using a polynomial approximation. A continuous-time Markov chain-governed volatility and return underlie the stock price generating process. We give European and lookback option prices under various conditions as well as discuss the precision and efficiency of our approach compared to other methods. The approximation methods are applicable for arbitrary regime settings and prove to be fast and accurate with multiple regimes. 


\section{North American Actuarial Journal}

17(3), 2013

HARTMAN, BRIAN M; GROENDYKE, CHRIS. Model selection and averaging in financial risk management. 216-228. Simulated asset returns are used in many areas of actuarial science. For example, life insurers use them to price annuities, life insurance, and investment guarantees. The quality of those simulations has come under increased scrutiny during the current financial crisis. When simulating the asset price process, properly choosing which model or models to use, and accounting for the uncertainty in that choice, is essential. We investigate how best to choose a model from a flexible set of models. In our regime-switching models the individual regimes are not constrained to be from the same distributional family. Even with larger sample sizes, the standard model-selection methods (AIC, BIC, and DIC) incorrectly identify the models far too often. Rather than trying to identify the best model and limiting the simulation to a single distribution, we show that the simulations can be made more realistic by explicitly modeling the uncertainty in the model-selection process. Specifically, we consider a parallel model-selection method that provides the posterior probabilities of each model being the best, enabling model averaging and providing deeper insights into the relationships between the models. The value of the method is demonstrated through a simulation study, and the method is then applied to total return data from the S\&P 500.

MACDONALD, BONNIE-JEANNE; JONES, BRUCE; MORRISON, RICHARD J; BROWN, ROBERT L; HARDY, MARY. Research and reality: A literature review on drawing down retirement financial savings. 181-215. How do, could, and should retirees draw down their financial savings? This article reviews over 100 papers on this topic from the perspective of individuals, families, governments, and financial institutions. Three significant conceptual/ methodological weaknesses in the existing literature are identified: (1) analysts have examined a limited range of self-managed drawdown strategies; (2) nearly all have ignored home ownership, pensions, debt, and government taxes and transfers when quantitatively evaluating alternative drawdown strategies; and (3) there is a well-acknowledged gap between the behavior implied by economic models and that of real-life individuals, particularly when it comes to voluntary annuitization. Expanding the set of drawdown strategies evaluated (e.g., including larger payouts when life expectancy is reduced after the onset of a significant health condition, or using savings as bridge income to delay the take-up of Social Security payments), refining the income concept used, and more exact modeling of the trade-offs underlying individual decision-making will likely increase the appeal of self-managed drawdown strategies and help resolve the "annuity puzzle" that has long dominated this line of research. It may also lead to advice and financial products that will better meet the needs of retirees.

TANG, QIHE; YUAN, ZHONGYI. Asymptotic analysis of the loss given default in the presence of multivariate regular variation. 253-271. Consider a portfolio of $n$ obligors subject to possible default. We propose a new structural model for the loss given default, which takes into account the severity of default. Then we study the tail behavior of the loss given default under the assumption that the losses of the $\mathrm{n}$ obligors jointly follow a multivariate regular variation structure. This structure provides an ideal framework for modeling both heavy tails and asymptotic dependence. Multivariate models involving Archimedean copulas and mixtures are revisited. As applications, we derive asymptotic estimates for the value at risk and conditional tail expectation of the loss given default and compare them with the traditional empirical estimates. 
WEI, XIAO; GAUDENZI, MARCELLINO; ZANETTE, ANTONINO. Pricing ratchet equityindexed annuities with early surrender risk in a CIR ++ model. 229-252. In this article we propose a lattice algorithm for pricing simple Ratchet equity-indexed annuities (EIAs) with early surrender risk and global minimum contract value when the asset value depends on the CIR ++ stochastic interest rates. In addition we present an asymptotic expansion technique that permits us to obtain a first-order approximation formula for the price of simple Ratchet EIAs without early surrender risk and without a global minimum contract value. Numerical comparisons show the reliability of the proposed methods.

North American Actuarial Journal

17(4), 2013

ARNOLD-GAILLE, SÉVERINE; SHERRIS, MICHAEL. Forecasting mortality trends allowing for cause-of-death mortality dependence. 273-282. Longevity risk is among the most important factors to consider for pricing and risk management of longevity products. Past improvements in mortality over many years, and the uncertainty of these improvements, have attracted the attention of experts, both practitioners and academics. Since aggregate mortality rates reflect underlying trends in causes of death, insurers and demographers are increasingly considering cause-of-death data to better understand risks in their mortality assumptions. The relative importance of causes of death has changed over many years. As one cause reduces, others increase or decrease. The dependence between mortality for different causes of death is important when projecting future mortality. However, for scenario analysis based on causes of death, the assumption usually made is that causes of death are independent. Recent models, in the form of Vector Error Correction Models (VECMs), have been developed for multivariate dynamic systems and capture time dependency with common stochastic trends. These models include long-run stationary relations between the variables and thus allow a better understanding of the nature of this dependence. This article applies VECMs to cause-of-death mortality rates to assess the dependence between these competing risks. We analyze the five main causes of death in Switzerland. Our analysis confirms the existence of a long-run stationary relationship between these five causes. This estimated relationship is then used to forecast mortality rates, which are shown to be an improvement over forecasts from more traditional ARIMA processes, which do not allow for cause-of-death dependencies.

BOYER, M MARTIN; NYCE, CHARLES M. An industrial organization theory of risk sharing. 283-296. Examining the global reinsurance market, we propose a new theory of optimal risk sharing that finds its inspiration in the economic theory of the firm. Our model offers a theoretical foundation for two empirical regularities that are observed in the reinsurance market: (1) the choice of specific attachment (the deductible) and detachment points (the policy limits or the retrocession); and (2) the vertical and horizontal tranching of reinsurance contracts. Using a two-factor cost model, we show how reinsurance should be optimally layered (with attachment and detachment points) for a given book of business in order to minimize the cost and total premium associated with catastrophic events.

INGRAM, DAVID; BUSH, ELIJAH. Collective approaches to risk in business: an introduction to plural rationality theory. 297-305. This article initiates a discussion regarding Plural Rationality Theory, which began to be used as a tool for understanding risk 40 years ago in the field of social anthropology. This theory is now widely applied and can provide a powerful paradigm to 
understand group behaviors. The theory has only recently been utilized in business and finance, where it provides insights into perceptions of risk and the dynamics of firms and markets. Plural Rationality Theory highlights four competing views of risk with corresponding strategies applied in four distinct risk environments. We explain how these rival perspectives are evident on all levels, from roles within organizations to macro level economics. The theory is introduced and the concepts are applied with business terms and examples such as company strategy, where the theory has a particularly strong impact on risk management patterns. The principles are also shown to have been evident in the run up to-and the reactions after-the 2008 financial crisis. Traditional "risk management" is shown to align with only one of these four views of risk, and the consequences of that singular view are discussed. Additional changes needed to make risk management more comprehensive, widely acceptable, and successful are introduced.

SHI, PENG; ZHANG, WEI. Managed care and health care utilization: specification of bivariate models using copulas. 306-324. This article studies the effect of managed care on health care utilization compared to traditional fee-for-service plans in private health insurance market. To construct our hypothesis, we build a game-theoretic model to study health care utilization under a two-sided moral hazard: of patients and providers. In econometric modeling, we employ a copula regression to jointly examine individuals' health plan choice and their utilization of medical care services, because of the endogeneity of insurance choice. The dependence parameter in the copula reflects the relation between the two outcomes, based on which the average treatment effects are further derived. We apply the methodology to a survey data set of the U.S. population and consider three types of curative care and three types of preventive care for the measurement of medical care utilization. We find that managed care is in general associated with higher care utilization. Evidence is also found on the underlying incentives of both patients and medical providers

Reproduced with the permission of Taylor \& Francis, http://www.tandfonline.com/loi/uaaj20 Available for downloading from:

http://www.tandfonline.com/action/athensLogin?return_url=http://www.tandfonline.com/toc/ uaaj20

http://www.soa.org/news-and-publications/publications/journals/naaj/naaj-detail.aspx

Reproduced with the permission of the Society of Actuaries.

Subscription details available from: Society of Actuaries, 475 N. Martingale Road, Schaumburg, ILL 60173 USA, www.soa.org

Scandinavian Actuarial Journal

3, 2013

BARGÈS, MATHIEU; LOISEL, STÉPHANE; VENEL, XAVIER. On finite-time ruin probabilities with reinsurance cycles influenced by large claims. 163-185. Market cycles play a great role in reinsurance. Cycle transitions are not independent from the claim arrival process: a large claim or a high number of claims may accelerate cycle transitions. To take this into account, a semiMarkovian risk model is proposed and analyzed. A refined Erlangization method is developed to compute the finite-time ruin probability of a reinsurance company. Numerical applications and comparisons to results obtained from simulation methods are given. The impact of dependency between claim amounts and phase changes is studied. 
RABEHASAINA, LANDY; TSAI, CARY CHI-LIANG. Ruin time and aggregate claim amount up to ruin time for the perturbed risk process. 186-212. We consider the classical Sparre-Andersen risk process perturbed by a Wiener process, and study the joint distribution of the ruin time and the aggregate claim amounts until ruin by determining its Laplace transform. This is first done when the claim amounts follow respectively an exponential/Phase-type distribution, in which case we also compute the distribution of recovery time and study the case of a barrier dividend. Then the general distribution is considered when ruin occurs by oscillation, in which case a renewal equation is derived.

ZHANG, ZHIMIN; YANG, HAILIANG; YANG, HU. On a Sparre Andersen risk model perturbed by a spectrally negative Lévy process. 213-239. In this paper, we consider a Sparre Andersen risk model perturbed by a spectrally negative Lévy process (SNLP). Assuming that the interclaim times follow a Coxian distribution, we show that the Laplace transforms and defective renewal equations for the Gerber-Shiu functions can be obtained by employing the roots of a generalized Lundberg equation. When the SNLP is a combination of a Brownian motion and a compound Poisson process with exponential jumps, explicit expressions and asymptotic formulas for the Gerber-Shiu functions are obtained for exponential claim size distribution and heavy-tailed claim size distribution, respectively.

Scandinavian Actuarial Journal

4, 2013

CHRISTIANSEN, MARCUS C. Safety margins for unsystematic biometric risk in life and health insurance. 286-323. In multistate life and health insurances, the pattern of states of the policyholder is random, thus exposing the insurer to an unsystematic biometric risk. For this reason safety margins are added on premiums and reserves. But in contrast to non-life insurance, traditionally the safety margins are not chosen explicitly but implicitly in form of a valuation basis of first order. If we define the implicit margins bottom-up, we are not able to control the level of safety that we finally reach for premiums and reserves. If we use a top-down approach, that means that we directly calculate explicit margins for premiums and reserves and then choose implicit safety margins that correspond to the explicit margins, we are able to control the total portfolio risk, but we have the problem that it is unclear how to allocate the total margin to partial margins for different transitions at different ages. Although the allocation of the total margin to the partial (implicit) margins is not relevant for the total portfolio risk, we have to pay attention since it can have a great effect on the calculation of surplus. In this paper we calculate asymptotic probability distributions for premiums and reserves of second order by using the functional delta method. As a result, we can not only determine the actual level of safety that is induced by given implicit safety margins, but we can also linearly decompose the total randomness of a portfolio to contributions that the different transition rates at different ages make to the total uncertainty. As a result we do not only get new insight into the sources of unsystematic biometric risk, but we also obtain a useful tool that allows to construct reasonable principles for the allocation of the total safety margin to implicit margins with respect to transitions and ages.

LIU, JINGZHEN; YIU, KA-FAI CEDRIC; SIU, TAK KUEN; CHING, WAI-KI. Optimal investment-reinsurance with dynamic risk constraint and regime switching. 263-285. We study an optimal investment-reinsurance problem for an insurer who faces dynamic risk constraint in a 
Markovian regime-switching environment. The goal of the insurer is to maximize the expected utility of terminal wealth. Here the dynamic risk constraint is described by the maximal conditional Value at Risk over different economic states. The rationale is to provide a prudent investment-reinsurance strategy by taking into account the worst case scenario over different economic states. Using the dynamic programming approach, we obtain an analytical solution of the problem when the insurance business is modeled by either the classical Cramer-Lundberg model or its diffusion approximation. We document some important qualitative behaviors of the optimal investment-reinsurance strategies and investigate the impacts of switching regimes and risk constraint on the optimal strategies.

\section{ZADEH, AMIN HASSAN; BILODEAU, MARTIN. Fitting bivariate losses with phase-type} distributions. 241-262. Maximum likelihood estimation and (parametric bootstrap) goodness-of-fit test are considered for bivariate phase-type distributions introduced by Assaf and colleagues. In a special case, the dependence structure of bivariate phase-type distributions is revealed. The results are used to fit a real bi-dimensional data set related to insurance losses (LOSS) and allocated loss adjustment expenses (ALAE). The fitted bivariate phase-type is used to obtain conditional quantiles and mean of ALAE for a given value of LOSS. The bivariate phase-type distribution meets all the requirements listed in the study by Klugman and Parsa.

\section{Scandinavian Actuarial Journal}

$$
5,2013
$$

GAJEK, LESLAW; RUDZ, MARCIN. Sharp approximations of ruin probabilities in the discrete time models. 352-382. According to Solvency II directive, each insurance company could determine solvency capital requirements using its own, tailor made, internal model. This highlights the urgency of having fast numerical tools based on practically-oriented mathematical models. From the Solvency II perspective discrete time framework seems to be the most relevant one. In this paper, we propose a number of fast and accurate approximations of ruin probabilities involving some integral operator and examine them along strictly theoretical as well as numerical lines. For a few claim distributions the approximations are shown to be exact. In general, we prove that they converge with an exponential rate to the exact ruin probabilities without any restrictive assumptions on the claim distribution. A fast algorithm to approximate ruin probabilities by a numerical fixed point of the involved integral operator is given. As an application, ruin probabilities for, e.g. normally and Weibull-distributed claims are computed. Comparisons with discrete time counterparts of some continuous time approximation methods are also carried out. Numerical studies show that our approximations are precise both for small and large values of the initial surplus u. In contrast, the empirical De Vylder-type ones strongly depend on the claim distributions and are less precise for small and medium values of $u$.

HONG, LIANG; SARKAR, JYOTIRMOY. Contingent means in multi-life models. 340-351. Multi-life models are useful in actuarial science for studying life contingency. Contingent probabilities are well-understood by most actuaries and are discussed extensively in the existing actuarial literature. However, the mean of a life in a multi-life model involving order of deaths is often found to be rather challenging to interpret by most actuaries who do not understand measure-theoretic probability. Standard textbooks on actuarial science or statistics do not elaborate on the correct interpretation of contingent means, leaving the actuaries at risk of making a blunder. This paper presents the correct interpretation both heuristically and rigorously 
using a non-measure-theoretic language, so that actuaries will be aware of some common misconceptions and avoid pitfalls in their work. The primary audience of this paper is practicing actuaries, actuarial students and actuarial educators. So we have given several actuarial applications. We hope that applied statisticians also will find this paper useful.

WANG, RUODU; PENG, LIANG; YANG, JINGPING. Jackknife empirical likelihood for parametric copulas. 325-339. For fitting a parametric copula to multivariate data, a popular way is to employ the so-called pseudo maximum likelihood estimation proposed by Genest, Ghoudi, and Rivest [Genest, C., Ghoudi, K. and Rivest, L.-P. 1995. A semiparametric estimation procedure of dependence parameters in multivariate families of distributions. Biometrika, 82: 543-552.]. Although interval estimation can be obtained via estimating the asymptotic covariance of the pseudo maximum likelihood estimation, we propose a jackknife empirical likelihood method to construct confidence regions for the parameters without estimating any additional quantities such as the asymptotic covariance. A simulation study shows the advantages of the new method in case of strong dependence or having more than one parameter involved.

ZHAO, BOJUAN BARBARA; LIANG, XIANGLIANG; ZHAO, WENKE; HOU, DELONG. Modeling of group-specific mortality in China using a modified Lee-Carter model. 383-402. The paper assesses sex-age-specific mortality rates of the four groups of people in China, the country, cities, towns, and counties, based on the mortality data from the China Population Statistics Yearbooks (1988-2009) using a newly proposed modified Lee-Carter model. The results show that in general, the expected age-specific mortality rates decrease over the years, and the decreasing speed increased in the past decade. During 2000-2008, the expected mortality rates decreased over the years for females of all ages and groups and males in cities, remained with no changes for males ages 13-36 in the country and towns, but increased for males ages 13-43 in counties. Predictions for 2009 are made based on the 2000-2008 data, and comparisons to the observed rates from an annual survey show that they match each other well except for males ages $13-43$ in counties, whose mortality rates reached record highs around 2005 , and bounced back to the level of 2000 in 2008 and was reduced a little further in 2009, benefiting from the promulgations and enforcements of some safety regulations by the government on construction and mining sites where most labors are from counties. The predicted age-specific mortality rates from the model are compared to the assumed rates in the China Life Insurance Mortality Table (2000-2003) promulgated by the China Insurance Regulatory Commission, and they show a great deal of similarity in terms of changing trends over the ages.

\section{Scandinavian Actuarial Journal}

$$
6,2013
$$

ALBRECHER, HANSJÖRG; CHEUNG, ERIC C K; THONHAUSER, STEFAN. Randomized observation periods for the compound Poisson risk model: the discounted penalty function. 424-452. In the framework of collective risk theory, we consider a compound Poisson risk model for the surplus process where the process (and hence ruin) can only be observed at random observation times. For Erlang(n) distributed inter-observation times, explicit expressions for the discounted penalty function at ruin are derived. The resulting model contains both the usual continuous-time and the discrete-time risk model as limiting cases, and can be used as an effective approximation scheme for the latter. Numerical examples are given that illustrate the effect of random observation times on various ruin-related quantities. 
CONSTANTINESCU, CORINA; KORTSCHAK, DOMINIK; MAUME-DESCHAMPS, VÉRONIQUE. Ruin probabilities in models with a Markov chain dependence structure. 453-476. In this paper we derive explicit expressions for the probability of ruin in a renewal risk model with dependence among the increments $\left(Z_{k}\right)_{k>0}$. We study the case where the dependence structure among $\left(Z_{k}\right)_{k>0}$ is driven by a Markov chain with a transition kernel that can be described via ordinary differential equations with constant coefficients.

WILLMOT, GORDON E. On mixing, compounding, and tail properties of a class of claim number distributions. 403-423. The mathematical structure underlying a class of discrete claim count distributions is examined in detail. In particular, the mixed Poisson nature of the class is shown to hold fairly generally. Using some ideas involving complete monotonicity, a discussion is provided on the structure of other class members which are well suited for use in aggregate claims analysis. The ideas are then extended to the analysis of the corresponding discrete tail probabilities, which arise in a variety of contexts including the analysis of the stop-loss premium.

Reproduced with the permission of Taylor \& Francis, http://www.tandf.co.uk/journals/SACT

South African Actuarial Journal

13,2013

BUTLER, MEGAN B J; HU, B; KLOPPERS, D. A comparison of probability of ruin and expected discounted utility as objective functions for choosing a post-retirement investment strategy. 185-219. Individuals in defined-contribution retirement funds currently have a number of options as to how to finance their post-retirement spending. The paper considers the ranking of selected annuitisation strategies by the probability of ruin and by expected discounted utility under different scenarios. 'Ruin' is defined as occurring when income falls below a given threshold, but does not relate to the extent of that deficit. If there is insufficient money to buy an inflation-linked annuity at retirement, then the minimisation of the probability of ruin tends to result in living annuities with a high equity content. This is because the objective function does not reflect the extent of shortfall of income or the investor's level of risk aversion. The authors argue that this is a limitation to using the minimisation of the probability of ruin. Expected discounted utility may be more difficult to apply in practice, because of the complexity of explaining the approach to investors and the need to estimate a greater number of parameters explicitly. The authors argue that the use of expected discounted utility is, however, likely to be more representative of most investors' perception of risk, and illustrate its use by applying an extended discounted utility model that caters for the bequest motive and different reference income levels.

CLUR, J C; DORRINGTON, ROB E; SCHRIEK, KARL A; LEWIS, P L. Modelling the mortality of members of group schemes in South Africa. 143-183. In this paper, the methodology underlying the graduation of the mortality of members of group schemes in South Africa underwritten by life insurance companies under group life-insurance arrangements is described and the results are presented. A multivariate parametric curve was fitted to the data for the working ages 25 to 65 and comparisons are made with the mortality rates from the SA85-90 ultimate rates for insured lives and the ASSA2008 AIDS and demographic model. The results show that the mortality of members of group schemes is lower than that of the general population, mortality decreasing with increasing salary, as would be expected. For males it was found that there were differences in 
mortality rates by industry for a given salary band, whereas for females these differences only occurred in the lower salary bands. Furthermore, there is evidence of the healthy-worker effect at ages 60 and above, where the mortality rates appear to level off or even decrease as age increases. This contrasts with the mortality rates from the SA85-90 ultimate rates for insured lives and the ASSA2008 AIDS and demographic model, which increase exponentially.

MARTIN, MARILYN; HAYES, MARK. Operational risk management: practical implications for the South African insurance industry. 39-95. Like its European counterparts, the South African insurance industry is moving towards its own risk-based regulatory regime, Solvency Assessment and Management (SAM). As a result greater focus is being placed on the appreciation of risks facing firms, of which operational risk forms a significant part. This paper aims to review operational risks as they pertain to South African insurers, both in internal risk-management practices and for the purposes of regulatory compliance. It presents principles and initiatives that have the potential to assist insurers in their identification and management of operational risks. A framework for the management of operational risk is discussed, as is the use of operational-loss data in this framework. Through an industry survey, this paper assesses perceptions towards operational risk, as well as views on the SAM regulations for the calculation of operational risk capital. Furthermore, high-level feasibility of an industry-wide operational-risk consortium database is studied.

RAMJEE, SHIVANI; KOOVERJEE, A; DREYER, K A. The construction of a price index for contributions to South African open medical schemes. 1-19. An accurate measure of the change in the price of medical-scheme cover over time is necessary to inform health and social-security policy, and would provide consumers, employers and the regulator with a useful benchmark. A medical-scheme contribution index based on gross contributions to open medical schemes is constructed using the Paasche formula and a sample of schemes for the period 2006 to 2010. The results of the index indicate a $17,48 \%$ increase in real contributions over the period.

RAMJEE, SHIVANI; SIBIYA, F G; DREYER, K A. The gender profile of the South African actuarial profession. 21-37. The aim of this paper is to contextualise the gender status of the South African actuarial profession, both historically and relative to elsewhere in the world, as well as to establish the current level of representation of women in the profession. The authors have investigated the extent to which women are represented in different age groups and at various stages of the qualification process. They find that $85 \%$ of Fellow members of the Actuarial Society in 2010 are male but that women represent at least $30 \%$ of student members and younger cohorts. Given that people enter the profession primarily from undergraduate degrees in actuarial science, the authors have analysed the relative performance of female students enrolling for an Actuarial Science degree at the University of Cape Town. They find that the proportion of entrants who are female has increased over time but that persistency rates for female students are lower than for male students. They identify the need for further research to establish the underlying reasons for the gender differentials in entrants to university programmes and persistency, and conclude that universities, actuarial employers and the profession have a role to play in improving the perception of the profession and the experiences of women in the classroom and workplace.

SCHRIEK, KARL A; LEWIS, P L; CLUR, J C; DORRINGTON, ROB E. The mortality of members of group schemes in South Africa. 97-142. In this paper, the mortality of members of group schemes underwritten by South African life insurance companies is investigated. The research 
provides some indication of the level or mortality of this population as a whole, which apart from being useful for costing group schemes in future could be used, to the extent that these data represent the mortality of those in formal employment, in the costing of a national retirement scheme. Rates of mortality are investigated by several demographic factors such as age, sex, salary and industry of employment.

THOMSON, R J; REDDY, T L. The Capital-Asset Pricing Model reconsidered: tests in real terms on a South African market portfolio comprising equities and bonds. 221-263. This paper extends previous work of the authors to reconsider the capital-asset pricing model (CAPM) in South Africa in real terms. As in that work, the main question this study aimed to answer remains: Can the CAPM be accepted in the South African market for the purposes of the stochastic modelling of investment returns in typical actuarial applications? To test the CAPM in real terms, conventional and index-linked bonds were included both in the composition of the market portfolio and in tests of the securities market line. For the investigation, quarterly total returns from the FTSE/JSE all-share index listed on the JSE Securities Exchange from 30 September 1964 to 31 December 2010 were used, together with yields on government bonds and consumer price indices over the same period. As expressed in the securities market line, the CAPM suggests that higher systematic risk, as measured by beta, is associated with higher expected returns, and that the relationship between expected return and beta is linear. In this investigation the abovementioned predictions of the CAPM were tested for the South African market. Regression tests both of the zero-beta and standard versions of the CAPM were made, using both prior betas and in-period betas. Hotelling's test was also applied, as well as a regression analysis. These tests were made for individual periods as well as for all periods combined.

Reproduced with the permission of the Actuarial Society of South Africa.

Available for downloading from: http://www.actuarialsociety.org.za/Professionalresources/ SAActuarialJournal.aspx

$$
\begin{aligned}
& \text { Variance } \\
& \text { 6(2), } 2012
\end{aligned}
$$

BARDIS, EMMANUEL THEODORE; MAJIDI, ALI; MURPHY, DANIEL M. A family of chainladder factor models for selected link ratios. 143-160. The models of Mack (1993) [Mack, T., Distribution-free calculation of the standard error of Chain Ladder reserve estimates, ASTIN Bulletin (1993) 23, 1993, 213-225] and Murphy (1994) [Murphy, D., Unbiased loss development factors, Proceedings of the Casualty Actuarial Society (1994) 81, 154-222] are expanded to a continuously indexed family of chain-ladder models by broadening the variance structure of the error term. It is shown that, subject to certain restrictions, an actuary's selected report-to-report factor can be considered the best linear unbiased estimate for some member of this family. The approach given in Murphy (1994) yields a mean square error estimate of the unpaid claim liability that is consistent with the actuary's selections.

BODOFF, NEIL M; GAN, YUNBO. An analysis of the market price of Cat bonds. 161-177. Existing models of the market price of cat bonds [catastophe bonds] are often too exotic or too simplistic; we present a model that is grounded in theory yet also tractable. We also intend for our analysis of cat bond pricing to shed light on broader issues relating to the theory of risk pricing. By analyzing several years of cat bond prices "when issued," we describe the market clearing 
issuance price of cat bonds as a linear function of expected loss, with parameters that vary by peril and zone. The results provide a compact form of describing market prices of cat bonds and thus provide a framework for measuring differences in prices across various perils and zones; the output also allows us to measure changes in the issuance price of cat bonds across different time periods. The results also suggest an overarching theory of risk pricing, in which price of risk depends on two factors: the first factor is the required rate of return on downside risk capital in a portfolio context, and the second factor is the uncertainty of the estimate of the expected loss.

DALEY, THOMAS V. Class ratemaking for workers compensation: new developments in loss development. 196-244. For loss cost filings beginning in October 2009, NCCI [National Council on Compensation Insurance, USA] implemented the largest set of changes in 40 years to the methodology used to determine class pure premiums in workers compensation.This paper describes the new loss development methodology NCCI has implemented, the applied research approach, and some analyses of actual results achieved after making the modifications. It illustrates how specific areas of class ratemaking were modified, namely, loss development, limiting large claims, and applying expected excess provisions.

ELING, MARTIN; MAREK, SEBASTIAN D. Do underwriting cycles matter? An analysis based on dynamic financial analysis. 131-142. The aim of this paper is to analyze the impact of underwriting cycles on the risk and return of non-life insurance companies. We integrate underwriting cycles in a dynamic financial analysis framework using a stochastic process, specifically, the Ornstein-Uhlenbeck process, which is fitted to empirical data and used to analyze the impact of these cycles on risk and return. We find that underwriting cycles have a substantial influence on risk and return measures. Our results have implications for managers, regulators, and rating agencies that use such models in risk management, e.g., to determine risk-based capital requirements.

ZHANG, YINGJIE. Risk-adjusted underwriting performance measurement. 178-195. To measure economic profits generated by an insurance policy during its lifetime, we compare the terminal assets of the policy account with certain break-even value. The break-even value is an increasing function of the claims risk and the asset investment risk. It can be calculated with closed-form formulas. We study policies with multiyear loss payments and tax payments. Profits from underwriting and from capital investment are measured separately. Relationships between the cost of capital and the risk-adjusted discount rate of loss are derived. Methods developed in this paper are also useful for fair premium calculation.

Available for downloading from: http://www.variancejournal.org/issues

Variance

$7(1), 2013$

BODOFF, NEIL M. Reinsurance credit risk: a market-consistent paradigm for quantifying the cost of risk. 11-28. Property-casualty insurance companies tend to buy reinsurance; when they do, they must address reinsurance credit risk. This paper advocates that companies should evaluate reinsurance credit risk with a market-consistent paradigm, which manifests two salient features: a probabilistic view of credit risk that assigns costs to low probability events, and a willingness to use market-based instruments for the purpose of quantifying the cost of risk. The proposed 
market-consistent paradigm facilitates a company's ability and willingness to measure, hedge, and optimize reinsurance credit risk.

MANGO, DONALD F; MAJOR, JOHN A; ADLER, AVRAHAM; BUNICK, CLAUDE. Capital tranching: a RAROC approach to assessing reinsurance cost effectiveness. 82-91. The current industry standard approach evaluates reinsurance effectiveness by calculating capital cost savings as the product of a fixed capital cost rate and the required capital which is released. Reinsurance is deemed value-creating if the resulting capital cost savings is more than the profit margin ceded to support the purchase-a Return On Risk-Adjusted Capital (RORAC) approach. In reality, however, insurers do not typically release capital as a result of a reinsurance purchase. Rather, capital is generally fixed for the planning cycle. Capital cannot be simultaneously fixed and risk- adjusted. Instead of a RORAC measure, a Risk-Adjusted Return On Capital (RAROC) can be calculated using fixed capital. This requires a means of calculating the risk-adjusted return as a function of the capital consumed. One such calculation can be done by replacing the capital with its reinsurance equivalent: a set of earnings stop-loss reinsurance covers, or what can be called Tranched Capital. Examples will show how Tranched Capital and RAROC can produce very different indicated reinsurance purchases than does the ISA. The RAROC approach is more consistent with realistic insurer capital management, and provides different interpretations of the cost-benefit tradeoffs of reinsurance.

MERZ, MICHAEL; WÜTHRICH, MARIO V. Estimation of tail development factors in the paid-incurred chain reserving method. 61-73. In many applied claims reserving problems in P\&C [property and casualty] insurance, the claims settlement process goes beyond the latest development period available in the observed claims development triangle. This makes it necessary to estimate so-called tail development factors which account for the unobserved part of the insurance claims. We estimate these tail development factors in a mathematically consistent way. This paper is a modification of the paid-incurred chain (PIC) reserving model of Merz and Wüthrich (2010) [M Merz and M. V. Wüthrich, Paid-incurred chain claims reserving method, Insurance: Mathematics and Economics 46, 2010, pp. 568-579]. This modification then allows for the prediction of the outstanding loss liabilities and the corresponding prediction uncertainty under the inclusion of tail development factors.

ROBBIN, IRA. The theory of split credibility. 29-60. This paper tackles the question: why should split credibility be better than credibility without a split? It corrects previous misunderstandings and presents new formulas showing how parameter uncertainty is reduced by use of unsplit credibility and then how it might be further reduced by introduction of a split. It derives the formulas for unsplit and split credibility when losses follow the widely used collective risk model (CRM). It then demonstrates that split credibility can sometimes be ineffective in a CRM context and can sometimes produce negative credibility values or inversions of the primary and excess credibilities. The paper concludes with a call for further research to find a stronger conceptual justification for the split credibility plan used in practice.

SATTAYATHAM, PAIROTE; SANGAROON, KIAT; KLONGDEE, WATCHARIN. Ruin probabilitybased initial capital of the discreet-time surplus process. 74-81. This paper studies an insurance model under the regulation that the insurance company has to reserve sufficient initial capital to ensure that ruin probability does not exceed the given quantity a. We prove the existence of the minimum initial capital. To illustrate our results, we give an example in approximating the minimum initial capital for exponential claims. 
Available for downloading from: http://www.variancejournal.org/issues

Reproduced with the permission of the Casualty Actuarial Society.

Access to Variance issues via: http://www.variancejournal.org/issues/

Subscription details available from: Casualty Actuarial Society, 4350 N. Fairfax Drive, Suite 250, Arlington, VA 22203. USA. Tel.: +1 (703) 276-3100; Fax: +1 (703) (703) 276-3108, office@casact.org. 